Review

\title{
Metal-organic frameworks for highly efficient oxygen electrocatalysis
}

\author{
Xiaobo He a,b,e, Fengxiang Yin a,b,c,d,e,*, Hao Wang a,c, Biaohua Chen c, Guoru Li a,b,e \\ a State Key Laboratory of Organic-Inorganic Composites, Beijing University of Chemical Technology, Beijing 100029, China \\ b Advanced Catalysis and Green Manufacturing Collaborative Innovation Center, Changzhou University, Changzhou 213164, Jiangsu, China \\ c College of Chemical Engineering, Beijing University of Chemical Technology, Beijing 100029, China \\ d Beijing Key Laboratory of Energy Environmental Catalysis, Beijing 100029, China \\ e Changzhou Institute of Advanced Materials, Beijing University of Chemical Technology, Changzhou 213164, Jiangsu, China
}

\section{A R T I C L E I N F}

\section{Article history:}

Received 30 October 2017

Accepted 26 December 2017

Published 5 February 2018

\section{Keywords:}

Metal-organic frameworks

Porous materials

Electrocatalysis

Oxygen reduction reaction

Oxygen evolution reaction

Energy storage and conversion

\begin{abstract}
A B S T R A C T
Metal-organic frameworks (MOFs) are a series of highly porous crystalline materials, which are built from inorganic metal nodes and organic linkers through coordination bonds. Their unique porous structural features (such as high porosity, high surface areas, and highly ordered nanoporous structures) and designable structures and compositions have facilitated their use in gas capture, separation, catalysis, and energy storage and conversion. Recently, the design and synthesis of pure MOFs and their derivatives have opened new routes to develop highly efficient electrocatalysts toward oxygen reduction reactions (ORR) and oxygen evolution reactions (OER), which are the core electrode reactions in many energy storage and conversion techniques, such as metal-air batteries and fuel cells. This review first discusses recent progress in the synthesis and the electrocatalytic applications of pure MOF-based electrocatalysts toward ORR or OER, including pure MOFs, MOFs decorated with active species, and MOFs incorporated with conductive materials. The following section focuses on the advancements of the design and preparation of various MOF-derived materials-such as inorganic nano- (or micro-) structures/porous carbon composites, pure porous carbons, pure inorganic nano- (or micro-) structured materials, and single-atom electrocatalysts-and their applications in oxygen electrocatalysis. Finally, we present a conclusion and an outlook for some general design strategies and future research directions of MOF-based oxygen electrocatalysts.
\end{abstract}

(C) 2018, Dalian Institute of Chemical Physics, Chinese Academy of Sciences. Published by Elsevier B.V. All rights reserved.

\section{Introduction}

Electrocatalytic oxygen reduction reactions (ORR) and oxygen evolution reactions (OER) are very important in the realm of electrochemistry to achieve energy storage and conversion through the transformation between oxygen and water. ORR (cathodic) and OER (anodic) are half-cell reactions in regenerative fuel cells and rechargeable metal-air batteries. Typically, a four-electron transfer mechanism is favorable, as shown in the following reactions (the standard potential is reported in ref-

\footnotetext{
* Corresponding author. Tel: +86-10-64412054; Fax: +86-10-64419619; E-mail: yinfx@mail.buct.edu.cn

This work was supported by the National Natural Science Foundation of China (21706010), the Natural Science Foundation of Jiangsu Province of China (BK20161200), the Fundamental Research Funds for the Central Universities (buctrc201526 and PYCC1706), the Changzhou Sci \& Tech Program (CJ20160007), the support from Advanced Catalysis and Green Manufacturing Collaborative Innovation Center and Changzhou University (ACGM2016-06-02 and ACGM2016-06-03).

DOI: 10.1016/S1872-2067(18)63017-7 | http://www.sciencedirect.com/science/journal/18722067 | Chin. J. Catal., Vol. 39, No. 2, February 2018
} 
erence to the reversible hydrogen electrode, $R H E)$ :

ORR: $\mathrm{O}_{2}+4 \mathrm{H}^{+}+4 \mathrm{e}^{-} \rightarrow 2 \mathrm{H}_{2} \mathrm{O}\left(E^{0}=1.23 \mathrm{~V}\right)$

OER: $2 \mathrm{H}_{2} \mathrm{O} \rightarrow \mathrm{O}_{2}+4 \mathrm{H}^{+}+4 \mathrm{e}^{-}\left(E^{0}=1.23 \mathrm{~V}\right)$

Although the elementary steps of ORR/OER may differ based on different mechanisms (dissociation (ORR)/recombination (OER), associative, or peroxo) and electrolytes (acidic, alkaline, or neutral), three types of oxygen species, $\mathrm{OH}^{*}, \mathrm{O}^{*}$ and $\mathrm{OOH}^{*}$, have been accepted as intermediates during ORR/OER processes (Fig. 1) [1]. High-energy barriers of bond breaking or formation and multiple steps of proton and electron transfer result in their sluggish kinetics. Meanwhile, the triple "liquid-solid-gas" interfaces, where the reactions occur, hinder fast kinetics. Therefore, efficient electrocatalysts are urgently required.

Among the as-developed oxygen electrocatalysts, platinum group metals (PGMs), such as Pt \& Pd (for ORR) and Ir \& Ru (for OER), are highly active but still suffer from high cost and low reserves. Another serious issue associated with PGMs is their poor durability under continuous operating conditions. Therefore, it is of great interest to develop low-cost and earth-abundant electrocatalysts with comparable or superior catalytic performance to PGMs [2-10]. For PGM-free electrocatalysts, metal-free electrocatalysts (typically with nonmetal dopants [11]) (e.g., N, S and P) and transition metal (TM)-based ones, such as metallic TM, TM-oxides, TM-hydroxides, TM-chalcogenides (sulfides and selenides), TM-phosphides, and TM-borates, have been widely investigated [12-14]. Most efforts aim to increase the number of exposed active sites and boost intrinsic activity. Many synthetic protocols have been proposed and put into practice $[13,15]$. Generally speaking, high loading or highly porous and open structures are required to increase the number of exposed active sites, while fine tuning the compositions via facile routes is expected to boost intrinsic activity. Most importantly, the structure and the composition of an oxygen electrocatalysts should be well matched, resulting in synergistic effects for achieving high activity. It is still challenging, however, to simultaneously increase the number of active sites and boost intrinsic activity to realize a highly efficient oxygen electrocatalyst. Fortunately, a class of porous materials with inherent nanopores (generally pore siz- es smaller than $100 \mathrm{~nm}$ ), namely metal-organic frameworks (MOFs), provides a promising route to design and prepare highly efficient oxygen electrocatalysts.

MOFs are constructed with metal nodes and organic linkers via their coordination effects, which have high surface areas and high porosity. In comparison with other conventional porous materials, such as activated carbons, mesoporous silica, and zeolites, the most attractive advantages of MOFs are their tunable and designable pore structures, compositions, and functions, which can be easily realized by selecting the proper metal nodes and organic linkers [16-18]. In other words, MOFs can be designed on account of the features of metal nodes and the characteristics of organic linkers. To facilitate the design of MOFs with specific structures, the design methods of "reticular chemistry" and "net-based approach" have been proposed by Yaghi et al. [19] and Robson [20], respectively, both of which are based on the theory of network topology. To realize the predesigned MOFs, efficient synthetic methods have been explored, such as liquid diffusion, hydrothermal (or solvothermal) methods, microwave-assisted methods, and mechanochemical synthetic methods [21-23]. Over the past decade, numerous kinds of MOFs (more than 20000) have been successfully synthesized by combining these design methods and various synthetic methods [22]. Recently, as the development of the properties and functionality of MOFs approach practical demands, some possible synthetic methods that can produce MOFs on a large scale also have been developed, such as electrochemical synthetic methods, flow chemistry synthesis, and spray drying [24]. Some manufacturers, such as BASF, MOF Technologies, and MOF Apps, already have the capability of producing some kinds of MOFs and are promoting the commercialization of MOFs [24]. Note that a synthetic method, especially for large-scale production, should meet the following requirements: low cost, high environmental sustainability, and reproducibility.

MOFs have many potential applications [25], including gas separation and storage [26], catalysis [27], photocatalysis [28], luminescence [29], chemical sensing [30], drug delivery [31], and energy storage and conversion [32]. Among the numerous functions of MOFs, the intrinsic activity of pure MOFs in many

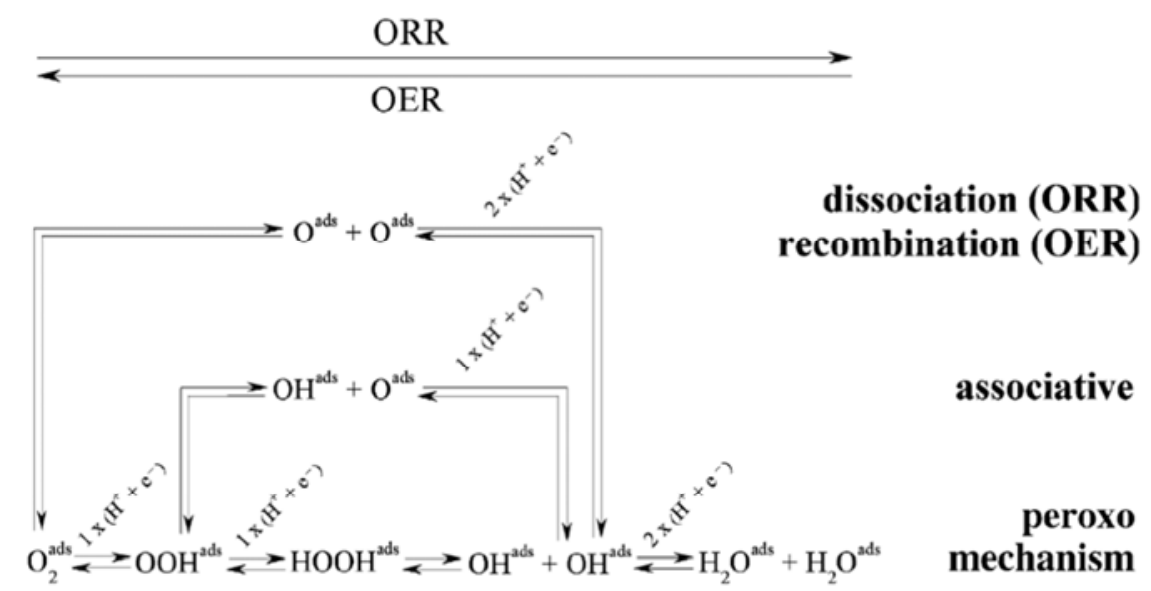

Fig. 1. Proposed ORR/OER mechanism. Reproduced with permission from Ref. [1], Copyright 2014 from WILEY-VCH. 
catalytic reactions mainly originates from their open metal nodes [18], which also play a role in oxygen electrocatalysis $[33,34]$. Although it is unlikely that all the metal nodes of an MOF would participate in catalysis, the generally high contents of metal nodes offer numerous opportunities to act as active sites. Furthermore, the high porosity and open structures of MOFs allow for full exposure of those active sites, whereas the designable compositions allow for tunable intrinsic activity. Thus, it is not surprising that MOFs can be regarded as excellent platforms to increase the number of active sites and boost intrinsic activity simultaneously. Recently, in practice, pure MOF-based materials have been applied in oxygen electrocatalysis [33-35]. Pure MOFs, however, still suffer from poor electronic conductivity. Pure MOFs could be incorporated with conductive materials, such as Ni foams [35], nanocarbons [36], and conductive glasses [37]; however, their electrocatalytic applications are limited in ORR and OER. An alternative route to high electrocatalytic activity is to take MOFs as self-sacrificial templates or precursors to generate electrocatalyst derivatives. After conversion, inevitably, the ordered pores of MOF precursors would be destroyed, and their surface areas would be reduced. Despite such negative results, the electronic conductivity or charge transfer efficiency, which is also crucial to high activity, always would be enhanced after the conversion of MOFs. Actually, porous structures and relatively high surface areas still can be achieved by the derived electrocatalysts, which are favorable for exposing their active sites. Furthermore, the compositions of the derived electrocatalysts can be tuned easily by adjusting the compositions of MOF precursors, thus exerting the effects on their intrinsic activity. Accordingly, this protocol shows great potential to obtain highly efficient oxygen electrocatalysts. To date, various MOF-derived oxygen electrocatalysts, with comparable or even superior performance to PGM catalysts, have been developed [32,38,39]. To offer an overview of this research field, this review mainly focuses on the recent advances in the synthesis and the oxygen electrocatalytic applications (ORR or OER) of pure MOF-based and MOF-derived electrocatalysts. The ORR and OER activity of some typical pure MOF-based and MOF-derived electrocatalysts are listed in Tables 1 and 2, respectively. At the end of this review, we present some possible design strategies and future research directions of MOF-based oxygen electrocatalysts.

\section{Pure MOF-based materials as oxygen electrocatalysts}

This section presents three categories of oxygen electrocatalysts based on pure MOFs: pure MOFs, MOFs decorated with active species, and MOFs incorporated with conductive materials. The section also provides an overview of their syntheses and the application as oxygen electrocatalysts.

Table 1

Summary of typical pure MOF-based oxygen electrocatalysts.

\begin{tabular}{|c|c|c|c|c|c|c|c|c|c|}
\hline \multirow{2}{*}{\multicolumn{2}{|c|}{ Oxygen electrocatalysts [Refs] }} & \multicolumn{2}{|c|}{ ORR } & \multicolumn{2}{|l|}{ OER } & \multirow{2}{*}{$\begin{array}{l}\text { Electrode and } \\
\text { e mass loading } \\
\left(\mathrm{mg} \mathrm{cm}^{-2}\right)\end{array}$} & \multicolumn{2}{|c|}{ Electrolyte } & \multirow[b]{2}{*}{ MOFs used } \\
\hline & & \multirow{2}{*}{$\begin{array}{c}\begin{array}{c}\text { Onset } \\
\text { potential }\end{array} \\
\begin{array}{c}0.820 \mathrm{~V} \text { vs. } \\
\text { RHE }^{\mathrm{a}}\end{array}\end{array}$} & \multirow{2}{*}{$\begin{array}{c}\begin{array}{c}\text { Half-wave } \\
\text { potential }\left(E_{1 / 2}\right)\end{array} \\
\text { Not provided }\end{array}$} & \multicolumn{2}{|c|}{$\begin{array}{l}\text { Potential at } 10 \text { Tafel slope } \\
\mathrm{mA} \mathrm{cm}^{-2}\left(E_{j=10}\right)\left(\mathrm{mV} \mathrm{dec}^{-1}\right)\end{array}$} & & \multicolumn{2}{|c|}{$\overline{\text { ORR OER }}$} & \\
\hline \multirow[t]{2}{*}{$\begin{array}{l}\text { Category } \\
-A\end{array}$} & $\mathrm{Ni}_{3}(\mathrm{HITP})_{2}[34]$ & & & - & - & $\mathrm{GC}^{\mathrm{b}}, \sim 0.026$ & $\begin{array}{c}0.1 \\
\mathrm{~mol} / \mathrm{L} \\
\mathrm{KOH}\end{array}$ & - & $\begin{array}{c}\mathrm{Ni}_{3}(\mathrm{HITP})_{2}(\mathrm{HITP}=2,3,6,7,10, \\
\text { 11-hexaiminotriphenylene \& } \\
\left.\mathrm{Ni}^{2+}\right)^{\mathrm{c}}\end{array}$ \\
\hline & $\begin{array}{l}\text { CoNi-MOF ultrathin } \\
\text { nanosheets [33] }\end{array}$ & - & - & 1.480 V vs. RHE & 42 & $\mathrm{GC}, \sim 0.200$ & - & $\begin{array}{c}1 \\
\mathrm{~mol} / \mathrm{L} \\
\mathrm{KOH}\end{array}$ & $\begin{array}{c}\text { CoNi-MOF } \\
(1,4 \text {-benzenedicarboxylate \& } \\
\left.\mathrm{Co}^{2+} \& \mathrm{Ni}^{2+}\right) \\
\end{array}$ \\
\hline \multirow[t]{3}{*}{$\begin{array}{l}\text { Category } \\
-B\end{array}$} & $\begin{array}{l}\text { Co/MIL-101(Cr)-O } \\
\text { [48] }\end{array}$ & $\begin{array}{c}-0.120 \mathrm{~V} \text { vs. } \\
\mathrm{Ag} / \mathrm{AgCl}\end{array}$ & $\begin{array}{l}-0.410 \mathrm{~V} \text { vs. } \\
\mathrm{Ag} / \mathrm{AgCl}\end{array}$ & $\begin{array}{l}0.750 \mathrm{~V} \text { vs. } \\
\mathrm{Ag} / \mathrm{AgCl}\end{array}$ & 122 & GC, $\sim 0.240$ & $\begin{array}{c}0.1 \\
\mathrm{~mol} / \mathrm{L}\end{array}$ & $\begin{array}{c}0.1 \\
\mathrm{~mol} / \mathrm{L}\end{array}$ & $\begin{array}{c}\text { MIL-101(Cr) } \\
\text { (1,4-benzenedicarboxylate acid }\end{array}$ \\
\hline & $\begin{array}{c}\text { Co/MIL-101(Cr)-R } \\
{[48]}\end{array}$ & $\begin{array}{l}-0.050 \mathrm{~V} \text { vs. } \\
\mathrm{Ag} / \mathrm{AgCl}\end{array}$ & $\begin{array}{l}-0.330 \mathrm{~V} \text { vs. } \\
\mathrm{Ag} / \mathrm{AgCl}\end{array}$ & $\begin{array}{l}0.940 \mathrm{~V} \text { vs. } \\
\mathrm{Ag} / \mathrm{AgCl}\end{array}$ & 156 & & $\mathrm{KOH}$ & $\mathrm{KOH}$ & $\left.\& \mathrm{Cr}^{3+} \& \mathrm{~F}^{-}\right)$ \\
\hline & $\begin{array}{c}\varepsilon-\mathrm{MnO}_{2} @ \mathrm{MOF}(\mathrm{Fe}) \\
{[49]}\end{array}$ & $\begin{array}{l}0.840 \mathrm{~V} \text { vs. } \\
\text { RHE }\end{array}$ & $\begin{array}{l}0.640 \mathrm{~V} \text { vs. } \\
\text { RHE }\end{array}$ & - & - & $\mathrm{GC}, \sim 0.243$ & $\begin{array}{c}0.1 \\
\mathrm{~mol} / \mathrm{L} \\
\mathrm{KOH}\end{array}$ & - & $\begin{array}{c}\mathrm{MOF}(\mathrm{Fe}) \\
(1,3,5-\text { benzene- } \\
\left.\text { tricarboxylate \& } \mathrm{Fe}^{3+} \& \mathrm{~F}^{-}\right)\end{array}$ \\
\hline \multirow[t]{3}{*}{$\begin{array}{l}\text { Category } \\
-\mathrm{C}\end{array}$} & $\begin{array}{c}\text { ZIF-67@N-doped } \\
\text { pomelo-peel-derived } \\
\text { carbon [55] }\end{array}$ & $\begin{array}{l}0.890 \text { V vs. } \\
\text { RHE }\end{array}$ & $\begin{array}{l}0.820 \mathrm{~V} \text { vs. } \\
\text { RHE }\end{array}$ & 1.640 V vs. RHE & 114 & GC, $\sim 0.240$ & $\begin{array}{c}0.1 \\
\mathrm{~mol} / \mathrm{L} \\
\mathrm{KOH}\end{array}$ & $\begin{array}{c}0.1 \\
\mathrm{~mol} / \mathrm{L} \\
\mathrm{KOH}\end{array}$ & $\begin{array}{c}\text { ZIF-67 } \\
\left.\text { (2-methylimidazole \& } \mathrm{Co}^{2+}\right)\end{array}$ \\
\hline & $\begin{array}{c}\mathrm{Fe} / \mathrm{Ni}-\mathrm{BTC} @ \mathrm{Ni} \text { foam } \\
{[35]}\end{array}$ & - & - & 1.500 V vs. RHE & 47 & $\begin{array}{l}\text { Ni foam, } \sim \text { not } \\
\text { provided }\end{array}$ & - & $\begin{array}{c}0.1 \\
\mathrm{~mol} / \mathrm{L} \\
\mathrm{KOH}\end{array}$ & $\begin{array}{c}\mathrm{Fe} / \mathrm{Ni}-\mathrm{BTC} \\
(1,3,5 \text {-benzene- } \\
\left.\text { tricarboxylate \& } \mathrm{Fe}^{3+} \& \mathrm{Ni}^{2+}\right)\end{array}$ \\
\hline & $\begin{array}{l}\mathrm{Ti}_{3} \mathrm{C}_{2} \mathrm{~T}_{x} \text {-Co-BDC } \\
\text { hybrid [56] }\end{array}$ & - & - & 1.64 V vs. RHE & 48.2 & $\mathrm{GC}, \sim 0.210$ & - & $\begin{array}{c}0.1 \\
\mathrm{~mol} / \mathrm{L} \\
\mathrm{KOH}\end{array}$ & $\begin{array}{c}\text { Co-BDC } \\
(1,4 \text {-benzenedicarboxylate \& } \\
\left.\text { Co }^{2+}\right)\end{array}$ \\
\hline
\end{tabular}

aThe abbreviation of "RHE" represents "reversible hydrogen electrode".

bThe abbreviation of "GC" represents "glassy carbon".

'The brackets include organic linkers and metal ions for constructing MOFs. 


\subsection{Pure MOFs (Category A)}

The pioneer work of using pure MOFs as OER electrocatalysts started from Marken's group in 2010 [40]. In that work, we detected the OER currents of a BasoliteTM F300 (constructed by 1,3,5-benzenetricarboxylate and $\mathrm{Fe}^{3+}$ ) under a water oxidation potential range in alkaline electrolyte. In 2012, Lin et al. [41] doped some catalytic Ir complexes into a highly stable and porous $\mathrm{Zr}_{6} \mathrm{O}_{4}(\mathrm{OH})_{4}(\mathrm{bpdc})_{6}(\mathrm{UiO}-67$, bpdc $=$ para-biphenyldicarboxylate and $\mathrm{Zr}^{4+}$ ) as OER electrocatalysts. The results indicated that the high turnover frequency (TOF) of the as-synthesized electrocatalysts in acidic electrolyte did not result from $\mathrm{IrO}_{2}$ nanoparticles that possibly were generated by the decomposition of organic ligands, because the $\mathrm{IrO}_{2}$ nanoparticles were less stable. Further experiments confirmed that the molecular origin of the OER activity was from MOFs. The first uses of pure MOFs as ORR electrocatalysts can be traced to 2012. In that work, Mao et al. [42] developed copper (II) benzene-1,3,5-tricarboxylate (Cu-BTC, BTC = 1,3,5-benzenetricarboxylate and $\mathrm{Cu}^{2+}$ and copper (II)-2,2'-bipyridinebenzene-1,3,5-tricarboxylate (Cu-bipy-BTC, bipy $=2,2^{\prime}$-bipyridine $\& \mathrm{Cu}^{2+}$ ). In $\mathrm{Cu}$-bipy-BTC, the bipy acted as the auxiliary ligand. This investigation demonstrated that Cu-bipy-BTC afforded much greater ORR activity and structural

Table 2

Overview of typical MOF-derived oxygen electrocatalysts.

\begin{tabular}{|c|c|c|c|c|c|c|c|c|c|}
\hline \multirow{2}{*}{\multicolumn{2}{|c|}{ Oxygen electrocatalysts [Refs] }} & \multicolumn{2}{|c|}{ ORR } & \multicolumn{2}{|c|}{ OER } & \multirow{2}{*}{$\begin{array}{l}\text { Electrode } \\
\text { and mass } \\
\text { loading } \\
\left(\mathrm{mg} \mathrm{cm}^{-2}\right)\end{array}$} & \multicolumn{2}{|c|}{ Electrolyte } & \multirow[b]{2}{*}{ MOFs used } \\
\hline & & $\begin{array}{c}\text { Onset } \\
\text { potential }\end{array}$ & $\begin{array}{c}\text { Half-wave } \\
\text { potential } \\
\left(E_{1 / 2}\right)\end{array}$ & $\begin{array}{l}\text { Potential at } \\
10 \mathrm{~mA} \mathrm{~cm}^{-2} \\
\quad\left(E_{j=10}\right)\end{array}$ & $\begin{array}{c}\text { Tafel } \\
\text { slope (mV } \\
\left.\text { dec }^{-1}\right)\end{array}$ & & ORR & OER & \\
\hline \multirow[t]{10}{*}{$\begin{array}{l}\text { Category } \\
-\mathrm{I}\end{array}$} & $\begin{array}{l}\text { NC nanotube } \\
\text { frameworks [61] }\end{array}$ & $\begin{array}{l}0.970 \text { V vs. } \\
\text { RHE }\end{array}$ & $\begin{array}{l}0.870 \mathrm{~V} \text { vs. } \\
\text { RHE }\end{array}$ & $\begin{array}{l}1.600 \mathrm{~V} \text { vs. } \\
\text { RHE }\end{array}$ & 93 & $\begin{array}{c}\mathrm{GC} \\
\sim 0.200\end{array}$ & $\begin{array}{c}0.1 \mathrm{~mol} / \mathrm{L} \\
\mathrm{KOH}\end{array}$ & $\begin{array}{c}1 \mathrm{~mol} / \mathrm{L} \\
\mathrm{KOH}\end{array}$ & $\begin{array}{c}\text { ZIF-67 } \\
\text { (2-methylimidazole \& } \mathrm{Co}^{2+} \text { ) }\end{array}$ \\
\hline & $\begin{array}{l}\text { N-doped } \\
\text { PC@Co-N-doped } \\
\text { graphitic carbon [62] }\end{array}$ & $\begin{array}{l}0.920 \text { V vs. } \\
\text { RHE }\end{array}$ & $\begin{array}{l}0.820 \mathrm{~V} \text { vs. } \\
\text { RHE }\end{array}$ & $\begin{array}{l}1.640 \text { V vs. } \\
\text { RHE }\end{array}$ & 91 & $\begin{array}{c}\mathrm{GC}, \\
\sim 0.400\end{array}$ & $\begin{array}{l}0.1 \mathrm{~mol} / \mathrm{L} \\
\mathrm{KOH}\end{array}$ & $\begin{array}{c}0.1 \mathrm{~mol} / \mathrm{L} \\
\mathrm{KOH}\end{array}$ & $\begin{array}{c}\text { ZIF-67 \& ZIF-8 } \\
\text { (2-methylimidazole \& } \mathrm{Co}^{2+} \text { ) \& } \\
\text { (2-methylimidazole \& } \mathrm{Zn}^{2+} \text { ) }\end{array}$ \\
\hline & ZnO-Co@NC [85] & $\begin{array}{l}0.980 \text { V vs. } \\
\text { RHE }\end{array}$ & $\begin{array}{l}0.840 \text { V vs. } \\
\text { RHE }\end{array}$ & $\begin{array}{l}1.620 \text { V vs. } \\
\text { RHE }\end{array}$ & 69 & $\begin{array}{c}\mathrm{GC} \\
\sim 0.240\end{array}$ & $\begin{array}{l}0.1 \mathrm{~mol} / \mathrm{L} \\
\mathrm{KOH}\end{array}$ & $\begin{array}{l}0.1 \mathrm{~mol} / \mathrm{L} \\
\mathrm{KOH}\end{array}$ & $\begin{array}{c}\mathrm{ZIF}(\mathrm{Co} / \mathrm{Zn}) \\
\text { (2-methylimidazole \& } \mathrm{Co}^{2+} \text { \& } \\
\mathrm{Zn}^{2+} \text { ) }\end{array}$ \\
\hline & $\mathrm{Co}_{-} \mathrm{SrCO}_{3} / \mathrm{NC}[86]$ & $\begin{array}{l}0.910 \text { V vs. } \\
\text { RHE }\end{array}$ & $\begin{array}{l}0.820 \text { V vs. } \\
\text { RHE }\end{array}$ & - & - & $\begin{array}{c}\text { GC, } \\
\sim 0.120\end{array}$ & $\begin{array}{l}0.1 \mathrm{~mol} / \mathrm{L} \\
\mathrm{KOH}\end{array}$ & - & $\begin{array}{c}\mathrm{MOF}(\mathrm{Co} / \mathrm{Sr}) \\
(1,2,4 \text {-triazole \& } \\
\text { 1,3,5-benzenetricarboxylate } \\
\left.\& \mathrm{Co}^{2+} \& \mathrm{Sr}^{2+}\right)\end{array}$ \\
\hline & 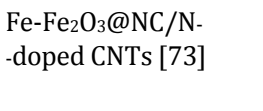 & $\begin{array}{l}0.920 \text { V vs. } \\
\text { RHE }\end{array}$ & $\begin{array}{l}0.720 \text { V vs. } \\
\text { RHE }\end{array}$ & - & - & $\begin{array}{c}\mathrm{GC} \\
\sim 0.240\end{array}$ & $\begin{array}{l}0.1 \mathrm{~mol} / \mathrm{L} \\
\mathrm{KOH}\end{array}$ & - & $\begin{array}{c}\text { MOG(Fe) } \\
(1,3,5 \text {-benzenetricarboxylate } \\
\left.\& \mathrm{Fe}^{3+}\right)\end{array}$ \\
\hline & $\begin{array}{l}\mathrm{Co}_{3} \mathrm{O}_{4} \text {-carbon porous } \\
\text { nanowire arrays [70] }\end{array}$ & $\begin{array}{c}\text { Not } \\
\text { provided }\end{array}$ & $\begin{array}{l}0.780 \text { V vs. } \\
\text { RHE }\end{array}$ & $\begin{array}{l}1.520 \text { V vs. } \\
\text { RHE }\end{array}$ & 70 & $\begin{array}{l}\mathrm{Cu} \text { foil, } \\
\sim 0.200\end{array}$ & $\begin{array}{l}0.1 \mathrm{~mol} / \mathrm{L} \\
\mathrm{KOH}\end{array}$ & $\begin{array}{c}0.1 \mathrm{~mol} / \mathrm{L} \\
\mathrm{KOH}\end{array}$ & $\begin{array}{c}\mathrm{MOF}(\mathrm{Co}) \\
(2,6-\text { naphthalene- } \\
\left.\text { dicarboxylate \& } \mathrm{Co}^{2+}\right)\end{array}$ \\
\hline & $\begin{array}{l}\mathrm{NiFeP}_{x} / \mathrm{N}, \mathrm{P} \\
\text { S-tri-doped PC [80] }\end{array}$ & - & - & $\begin{array}{l}1.495 \text { V vs. } \\
\text { RHE }\end{array}$ & 43 & $\begin{array}{c}\mathrm{GC} \\
\sim 0.200\end{array}$ & - & $\begin{array}{c}1 \mathrm{~mol} / \mathrm{L} \\
\mathrm{KOH}\end{array}$ & $\begin{array}{c}\mathrm{NiFe}_{2}-\mathrm{MIL}-88 \mathrm{~B} \\
\text { (terephthalate \& } \mathrm{Ni}^{2+} \& \mathrm{Fe}^{3+} \text { ) }\end{array}$ \\
\hline & $\begin{array}{l}\mathrm{Co}_{9} \mathrm{~S}_{8} @ \mathrm{~N}, \mathrm{~S} \text {-co-doped } \\
\text { honeycomb-like PC } \\
{[76]}\end{array}$ & $\begin{array}{c}-0.050 \mathrm{~V} \text { vs. } \\
\mathrm{Ag} / \mathrm{AgCl}\end{array}$ & $\begin{array}{c}-0.170 \mathrm{~V} \text { vs. } \\
\mathrm{Ag} / \mathrm{AgCl}\end{array}$ & - & - & $\begin{array}{c}\mathrm{GC} \\
\sim 0.400\end{array}$ & $\begin{array}{l}0.1 \mathrm{~mol} / \mathrm{L} \\
\mathrm{KOH}\end{array}$ & - & $\begin{array}{c}\text { MIL-101- } \mathrm{NH}_{2}(\mathrm{Al}) \\
\text { (2-aminoterephthalate \& } \\
\left.\mathrm{Al}^{3+}\right)\end{array}$ \\
\hline & $\mathrm{Co}_{0.85} \mathrm{Se} / \mathrm{NC}[79]$ & $\begin{array}{l}0.912 \text { V vs. } \\
\text { RHE }\end{array}$ & $\begin{array}{c}\text { Not } \\
\text { provided }\end{array}$ & $\begin{array}{l}1.550 \text { V vs. } \\
\text { RHE }\end{array}$ & 75 & $\begin{array}{c}\mathrm{GC} \\
\sim 0.408\end{array}$ & $\begin{array}{l}0.1 \mathrm{~mol} / \mathrm{L} \\
\mathrm{KOH}\end{array}$ & $\begin{array}{l}1 \mathrm{~mol} / \mathrm{L} \\
\mathrm{KOH}\end{array}$ & $\begin{array}{c}\text { ZIF-67 } \\
\text { (2-methylimidazole \& } \mathrm{Co}^{2+} \text { ) }\end{array}$ \\
\hline & $\begin{array}{l}\text { Hierarchical porous } \\
\mathrm{Cu}-\mathrm{N} / \mathrm{C}[63]\end{array}$ & $\begin{array}{l}0.914 \text { V vs. } \\
\text { RHE }\end{array}$ & $\begin{array}{c}0.813 \text { V vs. } \\
\text { RHE }\end{array}$ & - & - & $\begin{array}{c}\mathrm{GC} \\
\sim 0.250\end{array}$ & $\begin{array}{l}0.1 \mathrm{~mol} / \mathrm{L} \\
\mathrm{KOH}\end{array}$ & - & $\begin{array}{c}\text { Cu doped ZIF-8 } \\
\text { (2-methylimidazole \& } \mathrm{Cu}^{2+} \text { \& } \\
\left.\mathrm{Zn}^{2+}\right)\end{array}$ \\
\hline \multirow[t]{3}{*}{$\begin{array}{l}\text { Category } \\
\text {-II }\end{array}$} & $\begin{array}{l}\mathrm{N} \text { enriched } \\
\text { meso-microporous } \\
\text { carbon frameworks } \\
\text { /graphene [105] }\end{array}$ & $\begin{array}{c}0.881 \text { V vs. } \\
\text { RHE }\end{array}$ & $\begin{array}{l}0.822 \text { V vs. } \\
\text { RHE }\end{array}$ & - & - & $\begin{array}{c}\mathrm{GC} \\
\sim 0.250\end{array}$ & $\begin{array}{l}0.1 \mathrm{~mol} / \mathrm{L} \\
\mathrm{KOH}\end{array}$ & - & $\begin{array}{c}\text { ZIF-8 } \\
\text { (2-methylimidazole \& } \mathrm{Zn}^{2+} \text { ) }\end{array}$ \\
\hline & $\begin{array}{l}\text { Highly graphitized } \\
\text { N-doped PC [103] }\end{array}$ & $\begin{array}{c}-0.017 \text { V vs. } \\
\mathrm{Ag} / \mathrm{AgCl}\end{array}$ & $\begin{array}{c}-0.198 \mathrm{~V} \text { vs. } \\
\mathrm{Ag} / \mathrm{AgCl}\end{array}$ & - & - & $\begin{array}{c}\text { GC, } \\
\sim 0.102\end{array}$ & $\begin{array}{l}0.1 \mathrm{~mol} / \mathrm{L} \\
\mathrm{KOH}\end{array}$ & - & $\begin{array}{c}\text { ZIF-8 } \\
\text { (2-methylimidazole \& } \mathrm{Zn}^{2+} \text { ) }\end{array}$ \\
\hline & $\begin{array}{l}\text { Pyridinic-N doped PC } \\
\text { [107] }\end{array}$ & $\begin{array}{l}0.890 \text { V vs. } \\
\text { RHE }\end{array}$ & $\begin{array}{l}0.760 \mathrm{~V} \text { vs. } \\
\text { RHE }\end{array}$ & - & - & $\begin{array}{c}\mathrm{GC} \\
\sim 0.113\end{array}$ & $\begin{array}{l}0.1 \mathrm{~mol} / \mathrm{L} \\
\mathrm{KOH}\end{array}$ & - & $\begin{array}{c}\mathrm{Al}(\mathrm{OH})(\mathrm{BPYDC}) \\
(\mathrm{BPYDC}= \\
\text { 2,2'-bipyridine-5,5'-dicarboxy } \\
\left.\text { late \& } \mathrm{Al}^{3+}\right)\end{array}$ \\
\hline
\end{tabular}


Table 2 (continued)

\begin{tabular}{|c|c|c|c|c|c|c|c|c|c|}
\hline \multirow{2}{*}{\multicolumn{2}{|c|}{ Oxygen electrocatalysts [Refs] }} & \multicolumn{2}{|c|}{ ORR } & \multicolumn{2}{|c|}{ OER } & \multirow[b]{2}{*}{$\begin{array}{c}\text { Electrode } \\
\text { and mass } \\
\text { loading } \\
\left(\mathrm{mg} \mathrm{cm}^{-2}\right)\end{array}$} & \multicolumn{2}{|c|}{ Electrolyte } & \multirow[b]{2}{*}{ MOFs used } \\
\hline & & $\begin{array}{c}\text { Onset } \\
\text { potential }\end{array}$ & $\begin{array}{l}\text { Half-wave } \\
\text { potential } \\
\left(E_{1 / 2}\right)\end{array}$ & $\begin{array}{l}\text { Potential at } \\
10 \mathrm{~mA} \mathrm{~cm}^{-2} \\
\quad\left(E_{j=10}\right)\end{array}$ & $\begin{array}{c}\text { Tafel } \\
\text { slope } \\
\left(\mathrm{mV} \mathrm{dec}^{-1}\right)\end{array}$ & & ORR & OER & \\
\hline \multirow[t]{6}{*}{$\begin{array}{l}\text { Category } \\
\text {-II }\end{array}$} & N-doped PC [106] & $\begin{array}{l}1.020 \text { V vs. } \\
\text { RHE } \\
0.818 \text { V vs. } \\
\text { RHE } \\
1.03 \text { V vs. } \\
\text { RHE }\end{array}$ & $\begin{array}{l}0.902 \text { V vs. } \\
\text { RHE } \\
0.698 \text { V vs. } \\
\text { RHE } \\
0.818 \text { V vs. } \\
\text { RHE }\end{array}$ & - & - & $\begin{array}{c}\mathrm{GC}, \\
\sim 0.420\end{array}$ & $\begin{array}{c}0.1 \mathrm{~mol} / \mathrm{L} \\
\mathrm{KOH} \\
0.5 \mathrm{~mol} / \mathrm{L} \\
\mathrm{H}_{2} \mathrm{SO}_{4} \\
0.1 \mathrm{~mol} / \mathrm{L} \\
\text { phosphate } \\
\text { buffer solu- } \\
\text { tion }(\mathrm{pH}= \\
7.0)\end{array}$ & 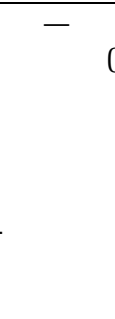 & $\begin{array}{c}\text { Zn-MOF-74 } \\
\text { (2,5-dihydroxyterephthalate } \\
\left.\& \mathrm{Zn}^{2+}\right)\end{array}$ \\
\hline & $\begin{array}{l}\text { N, S-co-doped porous } \\
\text { nanocarbon [109] }\end{array}$ & $\begin{array}{c}\text { Not } \\
\text { provided }\end{array}$ & $\begin{array}{c}-0.130 \text { V vs. } \\
\mathrm{Ag} / \mathrm{AgCl}\end{array}$ & - & - & $\begin{array}{c}\mathrm{GC}, \\
\sim 0.100\end{array}$ & $\begin{array}{l}0.1 \mathrm{~mol} / \mathrm{L} \\
\mathrm{KOH}\end{array}$ & - & $\begin{array}{c}\text { ZIF-8 } \\
\text { (2-methylimidazole \& } \mathrm{Zn}^{2+} \text { ) }\end{array}$ \\
\hline & $\begin{array}{l}\text { N, P-co-doped PC nano- } \\
\text { fibers [108] }\end{array}$ & $\begin{array}{c}-0.070 \mathrm{~V} \text { vs. } \\
\mathrm{Ag} / \mathrm{AgCl}\end{array}$ & $\begin{array}{l}-0.161 \mathrm{~V} \text { vs. } \\
\mathrm{Ag} / \mathrm{AgCl}\end{array}$ & - & - & $\begin{array}{c}\mathrm{GC}, \\
\sim 0.100\end{array}$ & $\begin{array}{l}0.1 \mathrm{~mol} / \mathrm{L} \\
\mathrm{KOH}\end{array}$ & - & $\begin{array}{c}\text { ZIF-8 } \\
\text { (2-methylimidazole \& } \mathrm{Zn}^{2+} \text { ) }\end{array}$ \\
\hline & B, N co-doped PC [100] & $\begin{array}{l}0.894 \text { V vs. } \\
\text { RHE }\end{array}$ & $\begin{array}{l}0.793 \text { V vs. } \\
\text { RHE }\end{array}$ & $\begin{array}{l}\sim 1.550 \mathrm{~V} \\
\text { vs. RHE }\end{array}$ & 117 & $\begin{array}{c}\mathrm{GC}, \\
\sim 0.400\end{array}$ & $\begin{array}{l}0.1 \mathrm{~mol} / \mathrm{L} \\
\mathrm{KOH}\end{array}$ & $\begin{array}{c}6 \mathrm{~mol} / \mathrm{L} \\
\mathrm{KOH}\end{array}$ & $\begin{array}{c}\text { MOF(Zn) (MC-BIF-1S) } \\
\text { (tetrakis(1-imidazolyl) } \\
\text { borate \& } \\
\text { 1,4-benzenebicarboxlate \& } \\
\text { imidazole \& } \mathrm{Zn}^{2+} \text { ) }\end{array}$ \\
\hline & $\begin{array}{l}\text { N, P, S- ternary-doped } \\
\text { PC [102] }\end{array}$ & $\begin{array}{c}-0.006 \mathrm{~V} \text { vs. } \\
\mathrm{Ag} / \mathrm{AgCl}\end{array}$ & $\begin{array}{l}\text { Not } \\
\text { provided }\end{array}$ & - & - & $\begin{array}{c}\mathrm{GC}, \\
\sim 0.102\end{array}$ & $\begin{array}{l}0.1 \mathrm{~mol} / \mathrm{L} \\
\mathrm{KOH}\end{array}$ & - & $\begin{array}{c}\text { MOF-5 } \\
\text { (1,4-benzenedicarboxylate } \\
\left.\& \mathrm{Zn}^{2+}\right)\end{array}$ \\
\hline & $\begin{array}{l}\text { Multi-hetero-atom (N, B, } \\
\text { P, S)-doped PCs [110] }\end{array}$ & $\begin{array}{l}0.904 \text { V vs. } \\
\text { RHE }\end{array}$ & $\begin{array}{c}\text { Not } \\
\text { provided }\end{array}$ & - & - & $\begin{array}{c}\mathrm{GC} \\
\sim 0.100 \\
\end{array}$ & $\begin{array}{c}0.1 \mathrm{~mol} / \mathrm{L} \\
\mathrm{KOH}\end{array}$ & - & $\begin{array}{c}\text { ZIF-8 } \\
\text { (2-methylimidazole \& } \mathrm{Zn}^{2+} \text { ) } \\
\end{array}$ \\
\hline \multirow[t]{6}{*}{$\begin{array}{l}\text { Category } \\
\text {-III }\end{array}$} & $\begin{array}{l}\text { Ni-Co mixed oxide } \\
\text { nanocages [113] }\end{array}$ & - & - & $\begin{array}{l}1.610 \text { V vs. } \\
\text { RHE }\end{array}$ & 50 & $\begin{array}{l}\text { GC, not } \\
\text { provided }\end{array}$ & - & $\begin{array}{c}1 \mathrm{~mol} / \mathrm{L} \\
\mathrm{KOH}\end{array}$ & $\begin{array}{l}\text { Ni-Co Prussian-Blue-Analog } \\
\left(\mathrm{CN}^{-} \& \mathrm{Ni}^{2+} \& \mathrm{Co}^{3+}\right)\end{array}$ \\
\hline & $\begin{array}{l}\text { Hollow } \mathrm{NiCo}_{2} \mathrm{O}_{4} \text { arrays } \\
{[114]}\end{array}$ & - & - & $\begin{array}{l}1.570 \text { V vs. } \\
\text { RHE }\end{array}$ & 72 & $\begin{array}{l}\text { Carbon } \\
\text { cloth, } \\
\sim 0.600\end{array}$ & - & $\begin{array}{l}1 \mathrm{~mol} / \mathrm{L} \\
\mathrm{KOH}\end{array}$ & $\begin{array}{c}\text { Co-MOF } \\
\text { (2-methylimidazole \& } \mathrm{Co}^{2+} \text { ) }\end{array}$ \\
\hline & $\begin{array}{l}\text { Hollow } \mathrm{Co}_{3} \mathrm{~S}_{4} @ \mathrm{MoS}_{2} \\
{[116]}\end{array}$ & - & - & $\begin{array}{l}1.560 \text { V vs. } \\
\text { RHE }\end{array}$ & 59 & $\begin{array}{c}\mathrm{GC} \\
\sim 0.283\end{array}$ & - & $\begin{array}{l}1 \mathrm{~mol} / \mathrm{L} \\
\mathrm{KOH}\end{array}$ & $\begin{array}{c}\text { ZIF-67 } \\
\text { (2-methylimidazole \& } \mathrm{Co}^{2+} \text { ) }\end{array}$ \\
\hline & $\begin{array}{l}\text { Hollow } \mathrm{CoSe}_{2} \\
\text { microspheres [117] }\end{array}$ & - & - & $\begin{array}{l}1.560 \text { V vs. } \\
\text { RHE }\end{array}$ & 79 & $\begin{array}{c}\mathrm{GC}, \\
\sim 0.354\end{array}$ & - & $\begin{array}{l}1 \mathrm{~mol} / \mathrm{L} \\
\mathrm{KOH}\end{array}$ & $\begin{array}{c}\text { Co-MOF }(1,3, \\
\text { 5-benzenetricarboxylate \& } \\
\left.\mathrm{Co}^{2+}\right)\end{array}$ \\
\hline & $\begin{array}{l}\text { CoP hollow polyhedron } \\
\text { [119] }\end{array}$ & - & - & $\begin{array}{l}1.63 \mathrm{~V} \text { vs. } \\
\text { RHE }\end{array}$ & 57 & $\begin{array}{c}\mathrm{GC}, \\
\sim 0.102\end{array}$ & - & $\begin{array}{l}1 \mathrm{~mol} / \mathrm{L} \\
\mathrm{KOH}\end{array}$ & $\begin{array}{c}\text { ZIF-67 } \\
\text { (2-methylimidazole \& } \mathrm{Co}^{2+} \text { ) }\end{array}$ \\
\hline & $\begin{array}{l}\text { Hierarchically struc- } \\
\text { tured } \mathrm{Co}_{3} \mathrm{O}_{4} @ \mathrm{CoP}[120]\end{array}$ & - & - & $\begin{array}{c}1.468 \mathrm{~V} \text { vs. } \\
\text { RHE }\end{array}$ & 51.4 & $\begin{array}{l}\text { Ni foil, } \\
\sim 1.000 \\
\end{array}$ & - & $\begin{array}{c}1 \mathrm{~mol} / \mathrm{L} \\
\mathrm{KOH}\end{array}$ & $\begin{array}{c}\text { ZIF-67 } \\
\left.\text { (2-methylimidazole \& } \mathrm{Co}^{2+}\right) \\
\end{array}$ \\
\hline \multirow[t]{4}{*}{$\begin{array}{l}\text { Category } \\
\text {-IV }\end{array}$} & $\begin{array}{l}\text { Isolated single-atom Fe/ } \\
\mathrm{N} \text {-doped PC [127] }\end{array}$ & $\begin{array}{l}0.986 \text { V vs. } \\
\text { RHE }\end{array}$ & $\begin{array}{l}0.900 \mathrm{~V} \text { vs. } \\
\text { RHE }\end{array}$ & - & - & $\begin{array}{c}\mathrm{GC}, \\
\sim 0.408\end{array}$ & $\begin{array}{l}0.1 \mathrm{~mol} / \mathrm{L} \\
\mathrm{KOH}\end{array}$ & - & $\begin{array}{c}\text { Fe doped ZIF-8 } \\
\text { (2-methylimidazole \& } \mathrm{Zn}^{2+} \\
\left.\& \mathrm{Fe}(\text { acac })_{3}\right)\end{array}$ \\
\hline & $\begin{array}{l}\text { Single atom Fe/N-doped } \\
\text { PC [128] }\end{array}$ & $\begin{array}{c}\text { Not } \\
\text { provided }\end{array}$ & $\begin{array}{l}0.850 \text { V vs. } \\
\text { RHE }\end{array}$ & - & - & $\begin{array}{c}\mathrm{GC}, \\
\sim 0.800\end{array}$ & $\begin{array}{c}0.5 \mathrm{~mol} / \mathrm{L} \\
\mathrm{H}_{2} \mathrm{SO}_{4}\end{array}$ & - & $\begin{array}{c}\text { Fe doped ZIF-8 } \\
\text { (2-methylimidazole \& } \mathrm{Zn}^{2+} \\
\left.\& \mathrm{Fe}^{3+}\right)\end{array}$ \\
\hline & $\begin{array}{l}\text { Single-atom Co/ } \\
\text { N-doped PC [93] }\end{array}$ & $\begin{array}{l}0.982 \text { V vs. } \\
\text { RHE }\end{array}$ & $\begin{array}{l}0.881 \text { V vs. } \\
\text { RHE }\end{array}$ & - & - & $\begin{array}{c}\mathrm{GC}, \\
\sim 0.408\end{array}$ & $\begin{array}{l}0.1 \mathrm{~mol} / \mathrm{L} \\
\mathrm{KOH}\end{array}$ & - & $\begin{array}{c}\text { Zn/Co bimetallic MOF } \\
\text { (2-methylimidazole \& } \mathrm{Co}^{2+} \& \\
\left.\mathrm{Zn}^{2+}\right)\end{array}$ \\
\hline & $\mathrm{CoO}_{x}$-ZIF-67 [129] & - & - & $\begin{array}{l}1.548 \mathrm{~V} \text { vs. } \\
\text { RHE }\end{array}$ & 70.3 & $\begin{array}{c}\mathrm{GC}, \\
\sim 0.200 \\
\end{array}$ & - & $\begin{array}{l}1 \mathrm{~mol} / \mathrm{L} \\
\mathrm{KOH}\end{array}$ & $\begin{array}{c}\text { ZIF-67 } \\
\text { (2-methylimidazole \& } \mathrm{Co}^{2+} \text { ) }\end{array}$ \\
\hline
\end{tabular}

stability, when compared with Cu-BTC, mainly because of the positive effects of bipy. These studies opened up a new route to develop oxygen electrocatalysts based on MOFs.

Our group's interest in the utilization of MOFs as oxygen electrocatalysts started in 2014. We developed a MOF(Fe) (1,3,5-benzenetricarboxylate $\left.\& \mathrm{~F}^{-} \& \mathrm{Fe}^{3+}\right)[43]$ as well as a bimetal MOF(Fe/Co) (1,3,5-benzenetricarboxylate \& $\mathrm{F}^{-}$\& $\mathrm{Fe}^{3+}$ \& $\mathrm{Co}^{2+}$ [ [44] as ORR electrocatalysts in alkaline electrolytes. Both 
MOFs had good crystalline structures with abundant micropores, large specific surface areas, and high thermal stability. The MOF(Fe) exhibited excellent ORR activity and afforded a current density of $-0.93 \mathrm{~mA} \mathrm{~cm}-2$ at $-0.3 \mathrm{~V}$ versus $\mathrm{Ag} / \mathrm{AgCl}$. The addition of Co into $\mathrm{MOF}(\mathrm{Fe})$ enabled $\mathrm{MOF}(\mathrm{Fe} / \mathrm{Co})$ to show an enhanced ORR activity with an increased current density of $-1.19 \mathrm{~mA} \mathrm{~cm}^{-2}$ at the same potential. For both of these catalysts, the ORR occurred through a two-electron pathway at low overpotentials and then shifted to a four-electron pathway at high overpotentials. Their excellent ORR activity was closely associated with fast oxygen diffusion and high utilization of catalytic sites, because of the high specific surface area and the microporous structure of MOFs. Notably, the bimetal $\mathrm{MOF}(\mathrm{Fe} / \mathrm{Co})$ also exhibited good OER activity. In other words, the MOF(Fe/Co) had bifunctional activity toward both ORR and OER. Our results demonstrated that tuning the compositions (such as metal nodes) of MOFs can greatly impact the ORR and OER activity.

In the same year, Wang et al. developed a Co-ZIF-9 ( $\mathrm{Co}^{2+-}$-benzimidazole) as an OER electrocatalyst. This work combined experimental study and density functional theory (DFT) calculation. The experimental results showed that it had the OER activity in a wide $\mathrm{pH}$ range. The theoretical calculation indicated that this catalyst was capable of activating water molecules by binding the OH-group to metal sites with low-activation barriers, while the eliminated proton would be accepted by the nearby benzimidazolate motifs. However, its current density was insufficient for practical applications. In a recent work, Tang et al. [33] successfully enhanced the OER activity of a pure MOF to an almost practical level. This MOF was constructed with bimetal nodes (Co and $\mathrm{Ni}$ ) and 1,4-benzenedicarboxylate as an organic linker, showing a two-dimensional (2D) ultrathin sheet-like nanostructure (denoted CoNi-UMOFNs in Fig. 2(A)). In comparison with bulk CoNi-MOFs, commercial $\mathrm{RuO}_{2}$ and the single metal ultrathin MOF nanosheets (i.e., Co-UMOFNs and Ni-UMOFNs), CoNi-UMOFNs exhibited superior OER activity with a very low overpotential of $189 \mathrm{mV}$ at $10 \mathrm{~mA} \mathrm{~cm}-2$ in alkaline electrolyte (Fig. 2(B) and Table 1). Furthermore, it also afforded excellent long-term durability and high Faradaic efficiency of $99.3 \%$. Such outstanding OER electrocatalytic performance of CoNi-UMOFNs primarily originated from the abundant unsaturated metal sites as active sites (Fig. 2(A)) and the coupling effects between $\mathrm{Co}$ and $\mathrm{Ni}$.

In spite of many advances, the oxygen electrocatalytic activity of pure MOFs is limited by poor electronic conductivity. New efforts have been made to construct charge-conductive MOFs. Mirceă et al. developed $\mathrm{Ni}_{3}(\mathrm{HITP})_{2}$ (HITP $=2,3,6,7,10$, 11-hexaiminotriphenylene $\& \mathrm{Ni}^{2+}$ ), a conductive 2D layered material (Fig. 2(C)) with electrical conductivity of $40 \mathrm{~S} \mathrm{~cm}^{-1}$ as an ORR electrocatalyst [34]. Under $\mathrm{O}_{2}$ atmosphere, $\mathrm{Ni}_{3}(\mathrm{HITP})_{2}$ reduced oxygen with an onset potential $(j=-50 \mu \mathrm{A} \mathrm{cm}-2)$ of $0.82 \mathrm{~V}$ versus RHE in $0.1 \mathrm{~mol} / \mathrm{L} \mathrm{KOH} \mathrm{(Fig.} \mathrm{2(D)} \mathrm{and} \mathrm{Table} \mathrm{1).}$ The measured ORR onset potential was competitive with the most active non-PGM ORR electrocatalysts reported so far. Durability tests revealed that this MOF could maintain 88\% of
(A)
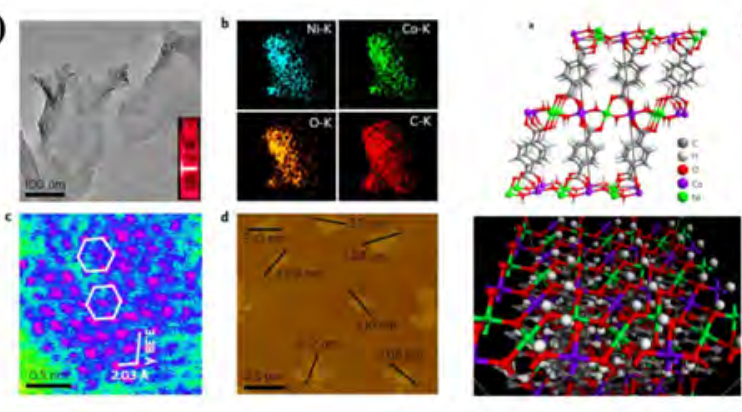

(B)

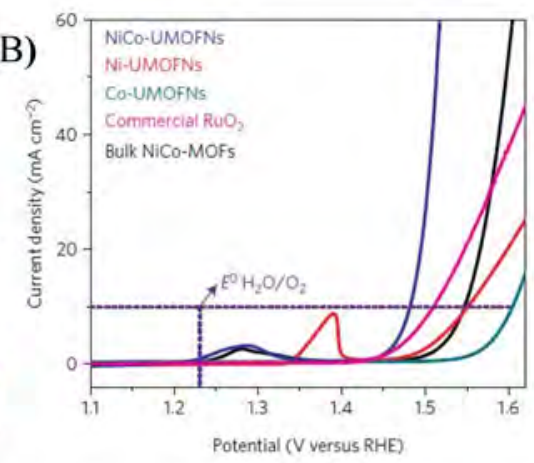

(C)

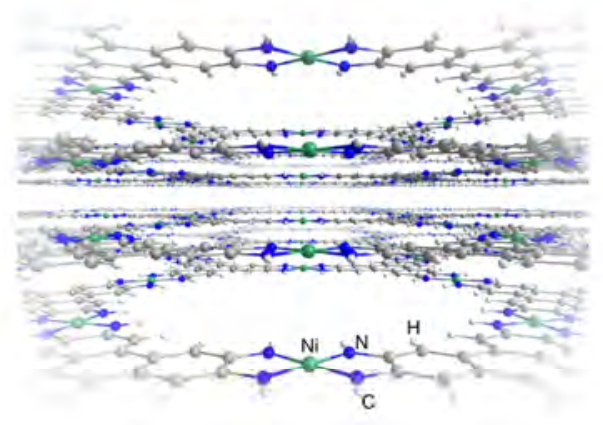

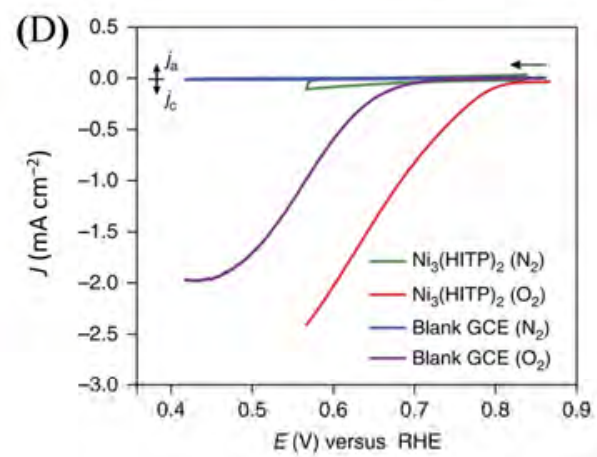

Fig. 2. (A) Physical characterization and crystal structure of ultrathin CoNi-MOF nanosheets (denoted CoNi-UMOFNs). (B) OER polarization curves of NiCo-UMOFNs, Ni-UMOFNs, Co-UMOFNs, $\mathrm{RuO}_{2}$, and bulk NiCo-MOFs in $\mathrm{O}_{2}$-saturated $1 \mathrm{~mol} / \mathrm{L} \mathrm{KOH.} \mathrm{Reproduced} \mathrm{with} \mathrm{permission} \mathrm{from} \mathrm{Ref.} \mathrm{[33],} \mathrm{Copy-}$ right 2016 Nature Publishing Group. (C) Perspective view of the 2D layered structure of $\mathrm{Ni}_{3}(\mathrm{HITP})_{2}$. (D) Polarization curves of $\mathrm{Ni}_{3}(\mathrm{HITP})_{2}$ and the blank glassy carbon electrode under $\mathrm{N}_{2}$ versus $\mathrm{O}_{2}$ atmosphere. Reproduced with permission from Ref. [34], Copyright 2016 Nature Publishing Group. 
(A)

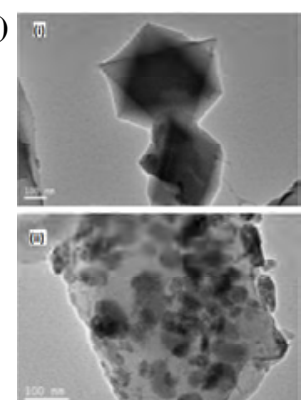

(C)

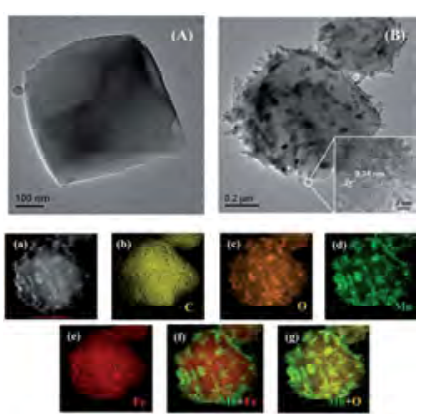

(B)

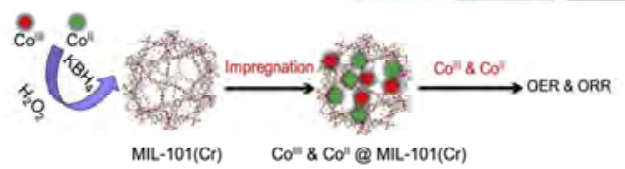

Fig. 3. (A) Transmission electron microscopy (TEM) images of (i) MIL-101(Cr) and (ii) $\alpha-\mathrm{MnO}_{2} / \mathrm{MIL}-101(\mathrm{Cr})$. Reproduced with permission from Ref. [47], Copyright 2014 Elsevier. (B) Illustration of the design and preparation of bifunctional electrocatalysts, i.e., $\mathrm{Co}^{\mathrm{III}}$ \& Co $@ @ M I L-101(\mathrm{Cr})$. Reproduced with permission from Ref. [48], Copyright 2015 Elsevier. (C) TEM images of MOF(Fe) and $\varepsilon-\mathrm{MnO}_{2} / \mathrm{MOF}(\mathrm{Fe})$ sample; and scanning transmission electron microscopy (STEM) image and corresponding elemental mapping on $\varepsilon-\mathrm{MnO}_{2} / \mathrm{MOF}(\mathrm{Fe})$ sample. Reproduced with permission from Ref. [49], Copyright 2015 Royal Society of Chemistry.

its initial current density over $8 \mathrm{~h}$. This study highlights conductive MOFs as a powerful platform for developing highly efficient oxygen electrocatalysts.

\subsection{MOFs decorated with active species (Category B)}

Apart from acting as electrocatalysts directly, porous MOFs, especially those with larger pore size and high stability (such as MIL-101(Cr) constructed by 1,4-benzenedicarboxylate \& $\mathrm{Cr}^{3+}$ \& $\mathrm{F}^{-}$[45]), can also be coated with other active species to further enhance their electrocatalytic performance. Das et al. [46] encapsulated an OER active Mn complex MnTD ([(terpy) $\left.\mathrm{Mn}(\mu-0)_{2} \mathrm{Mn}\right](\text { terpy) }]^{3+}$, terpy = 2,2':6',2'"-ter-pyridine) into

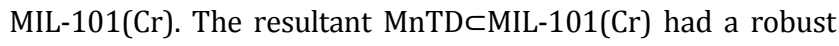
architecture, which could suppress the diffusion of active molecules to a neighboring pore or diffusing out. Our group embedded $\alpha-\mathrm{MnO}_{2}$ nanoparticles into MIL-101(Cr) matrix [47], resulting in $\alpha-\mathrm{MnO}_{2} / \mathrm{MIL}-101(\mathrm{Cr})$ composite electrocatalyst (Fig. 3(A)). The abundant micropores of the MIL-101(Cr) matrix surrounding the $\alpha-\mathrm{MnO}_{2}$ nanoparticles improved the accessibility of the reactant to catalytically active sites, while the synergistic effects between the MIL-101(Cr) matrix and $\alpha-\mathrm{MnO}_{2}$ nanoparticles enhanced the catalytic processes. As a result, $\alpha-\mathrm{MnO}_{2} / \mathrm{MIL}-101(\mathrm{Cr})$ afforded superior bifunctional activity toward both ORR and OER, compared with the MIL-101(Cr) matrix and $\alpha-\mathrm{MnO}_{2}$ nanoparticles. In another attempt, we decorated MIL-101(Cr) with active Co species [48]. The surface contents of $\mathrm{Co}^{\mathrm{III}}$ and $\mathrm{Co}^{\mathrm{II}}$ could be tuned via an oxidation or reduction treatment (Fig. 3(B)). The results indicated Co/MIL-101(Cr)-0 ("O" represents "oxidation"), with a higher surface Co ${ }^{\mathrm{III}}$ content, displayed higher OER activity (Table 1), while Co/MIL-101(Cr)-R ("R" represents "reduction"), with a higher surface Co ${ }^{\mathrm{II}}$ content, had superior ORR activity (Table 1). Both ORR and OER activity of the decorated MIL-101(Cr), however, surpassed that of the pure MIL-101(Cr). This was attributed to the porous and open structure of MIL-101(Cr), which favored the contact between oxygen species and active $\mathrm{Co}^{\text {III }}$ or $\mathrm{Co}^{\mathrm{II}}$ species as well as the interaction between MIL-101(Cr) and active Co species. In addition, our group also used another highly stable MOF (i.e., MOF(Fe), composed of 1,3,5-benzenetricarboxylate $\& \mathrm{Fe}^{3+} \& \mathrm{~F}^{-}$) to integrate $\mathrm{MnO}_{2}$ [49]. In the obtained $\varepsilon-\mathrm{MnO}_{2} @ \mathrm{MOF}(\mathrm{Fe})$ composite, $\varepsilon-\mathrm{MnO}_{2}$ nanorods were anchored on the MOF(Fe) matrix (Fig. 3(C)). The composite displayed enhanced catalytic activities toward ORR, in comparison to free $\varepsilon-\mathrm{MnO}_{2}$ and the physical mixtures of $\varepsilon-\mathrm{MnO}_{2}$ and $\mathrm{MOF}(\mathrm{Fe})$. The enhanced catalytic activities of the composites were due not only to the high specific surface areas and abundant micropores of $\mathrm{MOF}(\mathrm{Fe})$ but also to the interaction between $\varepsilon-\mathrm{MnO}_{2}$ nanorods and MOF (Fe).

\subsection{MOFs incorporated with conductive materials (Category C)}

The fundamental disadvantage of MOFs used directly as electrocatalysts is their poor electronic conductivity, which increases the resistance of charge transfer. Despite the early efforts to develop charge-conductive MOFs [34,50-52], an alternative strategy is to incorporate MOFs with conductive materials, such as graphene [53,54], porous carbons (PCs) [55], Ni foams [35], and MXene phased materials [56], which can enhance the charge transfer efficiency during oxygen electrocatalysis, as compared with pure MOFs.

In an early attempt, Loh et al. [53] synthesized a graphene-MOF hybrid electrocatalyst by reacting the pyridine-functionalized reduced graphene oxide (G-dye) with iron-porphyrin (FeP) (Fig. 4(A)), where FeP and pyridine acted as metalloporphyrin nodes and linkers, respectively. When 50 wt $\%$ of G-dye was introduced into this hybrid electrocatalyst, the (G-dye $50 \mathrm{wt} \%$-FeP) ${ }_{n}$ MOF had enhanced ORR activity in alkaline electrolyte (Fig. 4(B)), in comparison with other controlled samples. The improvements in catalytic activity could be attributed to the synergistic effects of the porosity of the framework, a large bond polarity that resulted from the nitrogen ligand of G-dye, and catalytically active FeP in the hybrid MOF. Loh et al. [54] continued to incorporate MOFs with graphene-based carbons. They prepared a graphene oxide and copper-centered MOF (Cu-MOF, constructed by 1,4-benzenedicarboxylate \& triethylene-diamine $\& \mathrm{Cu}^{2+}$ ) composite, which included a unique porous scaffold structure, that improved charge transport and synergistic interaction between $\mathrm{GO}$ and $\mathrm{Cu}-\mathrm{MOF}$. These favorable features of the GO/Cu-MOF composites facilitated charge and mass transfer, and thus, dramatically enhanced ORR and OER catalytic performance in acidic electrolyte.

Recently, our group synthesized N-doped pomelo-peel-derived carbon (NPC) with well-defined porosities and high N-doping content [55]. The NPC was further integrated with ZIF-67 (2-methylimidazole \& $\mathrm{Co}^{2+}$ ) to form a series of ZIF-67@NPC-2 hybrids (Fig. 4(C) and 4(D)). Among them, the optimal ZIF-67@NPC-2(2:1) exhibited the best OER catalytic 
(A)

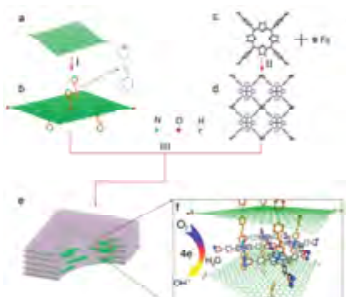

(C)

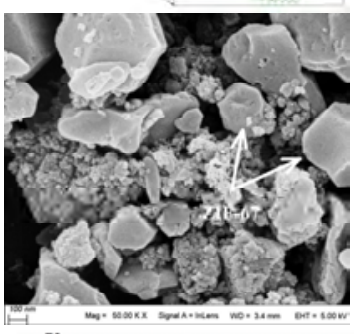

(E)

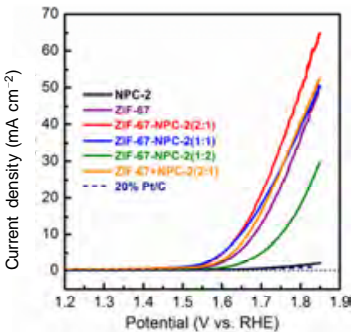

(B)
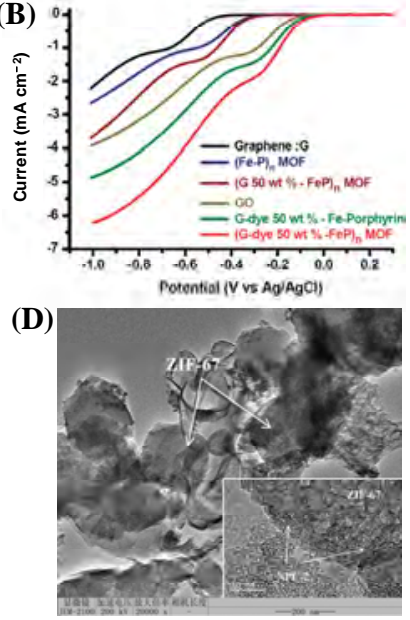

(F)

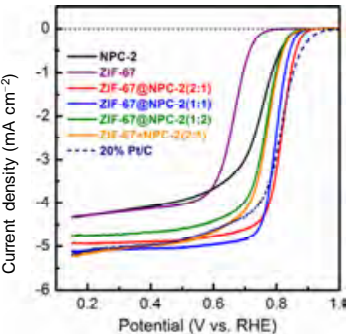

Fig. 4. (A) Synthetic routes to prepare graphene-porphyrin MOF. (B) ORR polarization curves of different samples in $\mathrm{O}_{2}$-saturated $0.1 \mathrm{~mol} / \mathrm{L}$ KOH. Reproduced with permission from Ref. [53], Copyright 2012 American Chemical Society. SEM (C) and TEM (D) images of ZIF-67-NPC-2(2:1). OER (E) and ORR (F) polarization curves of different samples $\mathrm{O}_{2}$-saturated $0.1 \mathrm{~mol} / \mathrm{L} \mathrm{KOH}$. Reproduced with permission from Ref. [55], Copyright 2017 Elsevier.

performance with a small potential $\left(E_{j}=10\right)$ of $1.61 \mathrm{~V}$ versus RHE at $10 \mathrm{~mA} \mathrm{~cm}^{-2}$ (Fig. 4(E)) and excellent catalytic durability. It also had the outperforming ORR catalytic performance with a more positive half-wave potential $\left(E_{1 / 2}\right)$ of $0.82 \mathrm{~V}$ versus RHE (Fig. 4(F)) and better catalytic durability, which was even better than those of 20 wt\% Pt/C. Therefore, ZIF-67@NPC-2(2:1) exhibited the best overall bifunctional catalytic activity $(\Delta E$ value of $0.79 \mathrm{~V}$, where $\Delta E=E_{j}=10-E_{1 / 2}$ ) of the developed ZIF-67@NPC-2 hybrids. It was closely associated with its highest content of Co- $\mathrm{N}_{4}$ moieties in ZIF-67, highest electrochemically active surface area, and strong interaction between ZIF-67 and NPC-2, ranking it among the best bifunctional non-PGM electrocatalysts. Since Jasinski et al. [57] developed a metaland N-co-doped carbon (M-N-C) in 1964, tremendous efforts have been made to develop M-N-C catalysts, typically through the pyrolysis of mixtures of $\mathrm{M} / \mathrm{N} / \mathrm{C}$ precursors for ORR or OER. In the aforementioned work, it is found that the nature of the central metal sites (Ni-N $\mathrm{N}_{4} \mathrm{C}$ [34], Fe- $\mathrm{N}_{4}-\mathrm{C}$ [53] and Co- $\mathrm{N}_{4}-\mathrm{C}$ [55]) directly influences their catalytic activity. Those metal sites, even in pure MOFs without pyrolysis, could also act as active sites for oxygen electrocatalysis. This would be an attractive way to construct highly active oxygen electrocatalysts.

In addition to carbon-based materials, other conductive materials also are applied as substrates to incorporate MOFs. Wang et al. used an electrochemical deposition technique to

deposit a series of MOF thin films on Ni foam, such as Fe-BTC, Ni-BTC, and Fe/Ni-BTC [35]. After optimization, the bimetallic Fe/Ni-MOF, with a Fe:Ni ratio of 1:12, had excellent OER activity with a notably low $E_{j}=10$ value $(\sim 1.50 \mathrm{~V}$ vs. RHE) and low Tafel slope $\left(\sim 47 \mathrm{mV} \mathrm{dec}^{-1}\right)$ in $\left.0.1 \mathrm{~mol} / \mathrm{L} \mathrm{KOH} \mathrm{(Table} 1\right)$. These values might be attributed to the synergistic effects of $\mathrm{Fe}$ and $\mathrm{Ni}$ sites, homogeneous distribution of active sites, high exposure of those active sites to electrolytes because of the high porosity of $\mathrm{Fe} / \mathrm{Ni}-\mathrm{BTC}$, and the high conductivity of Ni foam scaffold. Huang et al. [56] developed 2D hybrid nanosheets for OER, which were composed of CoBDC nanosheets as active materials and $\mathrm{Ti}_{3} \mathrm{C}_{2} \mathrm{~T}_{x}$ (MXene phase) nanosheets as conductive substrates. Such $\mathrm{Ti}_{3} \mathrm{C}_{2} \mathrm{~T}_{X}$-CoBDC hybrid nanosheets exhibited a low $E_{j=10}$ value of $\sim 1.64 \mathrm{~V}$ versus RHE and favorable kinetics with a low Tafel slope of $48.2 \mathrm{mV} \mathrm{dec}^{-1}$ during OER processes in 0.1 $\mathrm{mol} / \mathrm{L} \mathrm{KOH} \mathrm{(Table} \mathrm{1).} \mathrm{The} \mathrm{results} \mathrm{of} \mathrm{this} \mathrm{study} \mathrm{suggested} \mathrm{that}$ the MXene-phased $\mathrm{Ti}_{3} \mathrm{C}_{2} \mathrm{~T}_{x}$ could boost the OER activity of CoBDC in the $\mathrm{Ti}_{3} \mathrm{C}_{2} \mathrm{~T}_{x}$-CoBDC hybrid nanosheets, as the highly conductive $\mathrm{Ti}_{3} \mathrm{C}_{2} \mathrm{~T}_{x}$ could enhance the charge and ion transfer efficiencies, prevent the agglomeration of CoBDC nanosheets and facilitate the access of active sites of CoBDC to electrolytes.

To date, increasing MOFs have been getting involved as efficient OER electrocatalysts. Currently, there is a trend of using mixed-metal-ion MOFs (e.g., MOF(Fe/Co) [58], MOF(Fe/Ni) [35], and CoNi-UMOFNs [33]) rather than single-metal-site MOFs. From the ORR aspect, the nature of the metal sites (Ni-N4-C, Fe-N4-C, and Co-N4-C) directly influences the catalytic activity. Thus, the careful selection of metal ions and functional linkers is crucial to enhance the electrocatalytic performance of pure MOFs. In addition, decorating MOFs with other active species is another promising direction of pure MOFs in oxygen electrocatalysis application. Even though many advances have been made, the main issue associated with pure MOFs is still their poor electronic conductivity. Loading MOFs on conductive materials could mitigate this issue. The design and preparation of highly charge-conductive MOFs would be a better solution. No matter the strategy for the design and preparation for pure MOF-based oxygen electrocatalysts, the main goals are to increase the number of active sites and enhance intrinsic activity for them, thus improving the electrocatalytic performance.

\section{MOF-derived materials as ORR or OER electrocatalysts}

As discussed in the previous subsection, MOFs have the potential capability of catalyzing ORR or OER. Although they can be incorporated with conductive materials or designed as conductive MOFs to improve charge transfer efficiency, most MOFs still suffer from low conductivity, limiting their applications in oxygen electrocatalysis. Thus, a number of researchers have attempted another strategy that MOFs as precursors have been transformed into a variety of derived oxygen electrocatalysts $[59,60]$. Many related results have proven that the oxygen electrocatalytic performance outperformed their MOF precursors, showing great potential as highly efficient oxygen electrocatalysts. In the following subsection, we discuss four categories of recently reported MOF-derived electrocatalysts, including inorganic nano- (or micro-) structures/PC composites, pure PCs, 
pure inorganic nano- (or micro-) structured materials, and single-atom electrocatalysts.

\subsection{Inorganic nano- (or micro-) structures/PC composites (Category I)}

MOFs are constructed via the self-assembly of organic linkers and metal nodes. Generally speaking, when they are annealed in nonoxidative atmospheres (such as $\mathrm{N}_{2}, \mathrm{Ar}, \mathrm{H}_{2}$ ), organic linkers of MOFs are carbonized into PCs (usually hetero-atom doped PCs), while their metal nodes evolve into inorganic nano- (or micro-) structures. The derived PCs can provide high porosity, high electronic conductivity, and possible additional active sites for ORR or OER (primarily associated with the doped hetero-atoms, such as $\mathrm{N}, \mathrm{S}, \mathrm{P}$, and $\mathrm{B}$ ). In addition, the derived inorganic nano- (or micro-) structures mainly serve as active species. In most cases, the strongly synergistic effects between the PCs and the inorganic nano- (or micro-) structures are also favorable for oxygen electrocatalysis. Herein, some typical inorganic nano- (or micro-) structures/PC composites, such as metallic nanoparticles/PC, metal oxides/PC, metal chalcogenides/PC, metal phosphides/PC, and metal carbides/PC, are briefly discussed.

During a typical pyrolysis process of MOFs in nonoxidative atmospheres, the metal nodes can be reduced to metallic nanoparticles by the formed carbons, giving rise to metallic nanoparticles/PC composites. Among them, Fe, Co, Ni-based metallic nanoparticles/PC composites from their corresponding MOF-based precursors have been the most extensively investigated [61-66], mainly because of the high intrinsic activity of $\mathrm{Fe}$, Co, Ni-based species toward ORR and OER. For instance, recently, our group used a bimetallic $\mathrm{MOF}(\mathrm{Fe} / \mathrm{Co})$ precursor, a Prussian blue analogue (PBA), combined with carbon nanotubes (CNTs) to develop a highly efficient bifunctional oxygen electrocatalyst-that is, FeCo alloy@N-doped carbon (NC) anchored on CNTs (Figs. 5(A-1) and 5(A-2)) [67]. In comparison with the controlled samples, the developed FeCo alloy@NC anchored on CNTs showed superior bifunctional activity toward both ORR and OER in alkaline electrolytes, as indicated in Fig. 5(A-3). This superiority was attributed mainly to the synergistic effects from the FeCo alloy nanoparticles core, NC shell, and CNTs as conductive promoters. Apart from the high bifunctional activity, this oxygen electrocatalyst also afforded excellent performance in a Li-air battery with a high specific capacity of more than $5000 \mathrm{~mA} \mathrm{~h} \mathrm{g-1}^{-1}$ and good cycle stability. In addition, the recently explored $\mathrm{Cu}$-based electrocatalysts have attracted interest as oxygen electrocatalysis $[63,68]$, because copper $(\mathrm{Cu})$ has an intrinsic ORR activity close to that of Pt in the volcano plot [69]. On the basis of the potential capability of $\mathrm{Cu}$ in oxygen electrocatalysis, Zheng et al. [68] developed a $\mathrm{Cu}-$ and Co-embedded N-doped PCs (CuCo@NC) for ORR, which was derived from a ZIF-67/Cu(OH $)_{2}$ hybrid precursor. Thanks to abundant dual-metal active sites, enhanced N-doping level, high porosity, and high conductivity that benefited from the introduction of $\mathrm{Cu}$, the prepared CuCo@NC exhibited high ORR activity with a positive onset potential of $0.960 \mathrm{~V}$ versus RHE and half-wave potential of $0.884 \mathrm{~V}$ versus RHE in alkaline me- dia. These values are comparable to those of $30 \mathrm{wt} \% \mathrm{Pt} / \mathrm{C}$ (1.038 and $0.842 \mathrm{~V}$ vs. RHE, respectively). Chen et al. [63] tuned the coordination structures between $\mathrm{Cu}$ species and NCs and successfully obtained the highly active $\mathrm{Cu}-\mathrm{N}$ sites in the hierarchical N-doped PCs for ORR. To achieve this, they first synthesized $\mathrm{Cu}$-doped ZIF-8 polyhedrons and followed this by pyrolysis in $\mathrm{N}_{2}$. The obtained Cu-N/C electrocatalysts, with abundant mesopores and micropores, had high specific areas and $\mathrm{N}$-doping levels. Most importantly, the hybrid $\mathrm{Cu}^{0}-\mathrm{Cu}(\mathrm{II})-\mathrm{N}$ active sites, with high activity toward ORR, were embedded in the hierarchical PC matrix, where $\mathrm{Cu}$ (II) coordinated with $\mathrm{Cu}^{0}$ metallic nanoparticles and the doped $\mathrm{N}$ in the PCs. As a result, the optimized $25 \% \mathrm{Cu}-\mathrm{N} / \mathrm{C}$ afforded comparable ORR activity to that of $30 \mathrm{wt} \% \mathrm{Pt} / \mathrm{C}$ in alkaline solutions, and it showed excellent performance in a $\mathrm{Zn}$-air battery.

Apart from the metallic nanoparticles/PC composites discussed earlier, metal oxides/PC composite is another common type of oxygen electrocatalysts that has been derived from MOFs (generally using organic linkers containing oxygen). Similar to metallic nanoparticles/PC composites, Fe, Co, Ni-based MOFs are extensively utilized as precursors to develop $\mathrm{Fe}$, Co, Ni-based oxides/PCs composites for oxygen electrocatalysis,

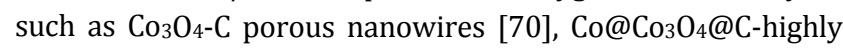
ordered PC matrix [71], Co@ $\mathrm{Co}_{3} \mathrm{O}_{4} / \mathrm{CNT}$-grafted NC polyhedrons [72], $\mathrm{Fe}_{-} \mathrm{Fe}_{2} \mathrm{O}_{3} @ \mathrm{NC} / \mathrm{N}$-doped CNTs [73], and $\mathrm{Co}_{x} \mathrm{Ni}_{1-x} @ \mathrm{Co}_{y} \mathrm{Ni}_{1-y} \mathrm{O} @ \mathrm{C}$ [74]. For example, our group developed a highly active ORR electrocatalyst based on an $\mathrm{Fe}-\mathrm{Fe}_{2} \mathrm{O}_{3}$ hybrid nanostructure using an Fe-based metal-organic gel [MOG(Fe)] [73]. During the synthetic procedure (Fig. 5(B-1)), a mixture of MOG (Fe), CNTs and urea (the N-doping source) was easily prepared. After pyrolysis of the mixture in $\mathrm{N}_{2}$ at $700{ }^{\circ} \mathrm{C}$, the obtained electrocatalyst (denoted MOG(Fe)/urea/CNTs-700) was constructed by $\mathrm{Fe}-\mathrm{Fe}_{2} \mathrm{O}_{3} @ \mathrm{NC}$ core-shell nanoparticles and their anchored N-doped CNTs (Figs. 5(B-2)-5(B-4)). The electrocatalytic evaluation indicated that MOG(Fe)/urea/CNTs-700 exhibited superior ORR activity to other controlled samples in alkaline media (Fig. 5(B-5)), and the activity was comparable to that of commercial $20 \mathrm{wt} \% \mathrm{Pt} / \mathrm{C}$. Notably, this electrocatalyst also showed higher ORR long-term durability and tolerance against methanol, as compared with $20 \mathrm{wt} \% \mathrm{Pt} / \mathrm{C}$. Thus, it is a promising electrocatalyst for ORR and fuel cells. Our thorough investigation demonstrated that the inner $\mathrm{Fe}_{2} \mathrm{Fe}_{2} \mathrm{O}_{3}$ hybrid nanoparticles and their thin outer NC shells play key roles in its high ORR activity. The $\mathrm{Fe}-\mathrm{Fe}_{2} \mathrm{O}_{3}$ hybrid nanoparticles can enhance the charge transfer efficiency between the electrodes and the electrolytes at the macro-scale, as compared with the fully oxidized $\mathrm{Fe}_{2} \mathrm{O}_{3}$ nanoparticles. In addition, strong charge transfer would exist between the inner $\mathrm{Fe}_{-} \mathrm{Fe}_{2} \mathrm{O}_{3}$ hybrid nanoparticles and their thin outer NC shells at the nanoscale, which could benefit the adsorption and dissociation of oxygen on active sites of the outer NC shells, thus promoting ORR activity [75].

Furthermore, the other metal compounds/PC composites that are derived from MOFs also have attracted significant interest, such as metal sulfides [76-78], metal selenides [79], metal phosphides [80,81], and metal carbides [82-84]. Various routes can be applied to realize the formation of those composites. One of them is the direct pyrolysis of pure MOFs or modi- 

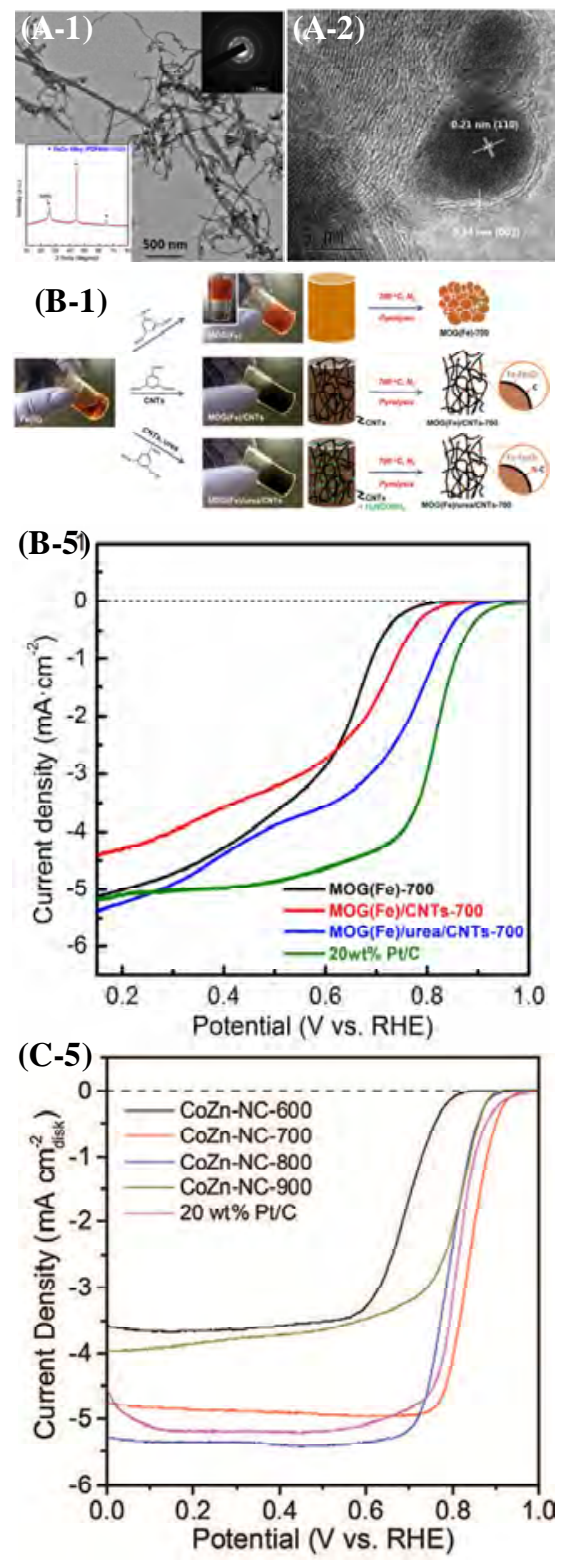

(D-1)

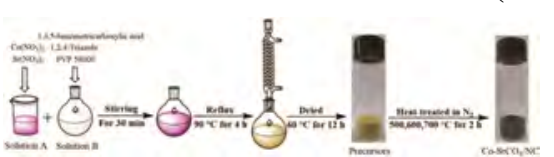

(A-3)
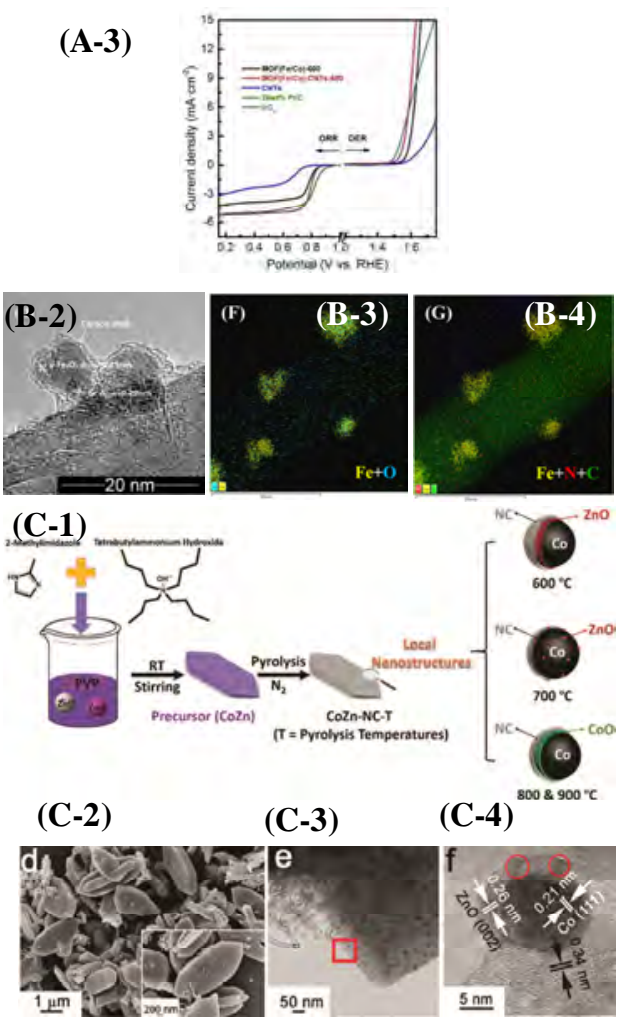

(C-6)

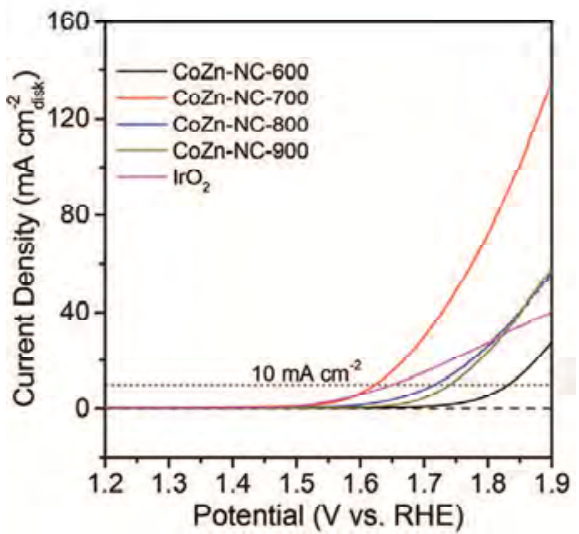

(D-2)

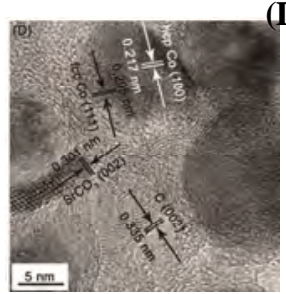

Fig. 5. (A-1) TEM image of MOF(Fe/Co)-CNTs-600, (A-2) HRTEM image of MOF(Fe/Co)-CNTs-600, and (A-3) ORR/OER polarization curves of the used samples and commercialized $\mathrm{IrO}_{2}$ for OER and $20 \mathrm{wt} \% \mathrm{Pt} / \mathrm{C}$ for ORR in $\mathrm{O}_{2}$-saturated $0.1 \mathrm{~mol} / \mathrm{L} \mathrm{KOH}$. Reproduced with permission from Ref. [67], Copyright 2017 Elsevier. (B-1) Illustration of the fabrication process of various precursors based on MOG(Fe) and their derivatives, (B-2) HRTEM image of MOG(Fe)/urea/CNTs-700, (B-3) and (B-4) element mapping of MOG(Fe)/urea/CNTs-700, and (B-5) ORR polarization curves of various electrocatalysts derived from MOG(Fe)-based precursors and $20 \mathrm{wt} \% \mathrm{Pt} / \mathrm{C}$ in $\mathrm{O}_{2}$-saturated $0.1 \mathrm{~mol} / \mathrm{L} \mathrm{KOH}$. Reproduced with permission from Ref. [73], Copyright 2017 Elsevier. (C-1) Illustration of the preparation of MO-Co@NC (M = Zn or Co), (C-2) SEM image of ZnO-Co@NC prepared at 700 드, i.e., denoted as CoZn-NC-700, (C-3) TEM image of CoZn-NC-700, (C-4) HRTEM image of CoZn-NC-700, (C-5) ORR polarization curves of the electrocatalysts prepared at different pyrolysis temperatures and $20 \mathrm{wt} \% \mathrm{Pt} / \mathrm{C}$ in $\mathrm{O}_{2}$-saturated $0.1 \mathrm{~mol} / \mathrm{L} \mathrm{KOH}$, and (C-6) OER polarization curves of the electrocatalysts prepared at different pyrolysis temperatures and $\mathrm{IrO}_{2}$ in $\mathrm{O}_{2}$-saturated $0.1 \mathrm{~mol} / \mathrm{L} \mathrm{KOH}$. Reproduced with permission from Ref. [85], Copy-

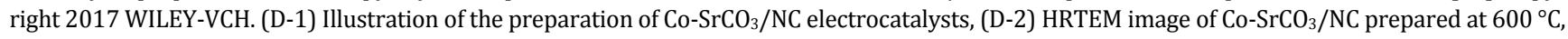
and (D-3) ORR polarization curves of the electrocatalysts prepared at different pyrolysis temperatures and $20 \mathrm{wt} \% \mathrm{Pt} / \mathrm{C}$ in $\mathrm{O}_{2}$-saturated $0.1 \mathrm{~mol} / \mathrm{L}$ KOH. Reproduced with permission from Ref. [86], Copyright 2017 Royal Society of Chemistry. The ORR polarization curves were all collected at 1600 rpm with a sweep rate of $5 \mathrm{mV} \mathrm{s}^{-1}$, while the OER polarization curves were all recorded at a sweep rate of $5 \mathrm{mV} \mathrm{s}^{-1}$. 
fied MOFs. For instance, Tang et al. [84] directly carbonized Fe-based MOF nanoparticles, that is, MIL-88B-NH (2-aminoterephtalate \& $\mathrm{Fe}^{3+}$ ), to form $\mathrm{Fe}-\mathrm{Fe}_{3} \mathrm{C}$ /porous $\mathrm{NC}$ nanoparticles. As compared with the carbonized microparticles from the microsized MIL-88B- $\mathrm{NH}_{3}$, the $\mathrm{Fe}-\mathrm{Fe}_{3} \mathrm{C}$ /porous $\mathrm{NC}$ nanoparticles afforded high ORR activity and selectivity as well as high methanol tolerance in alkaline electrolytes. Moreover, these attributes were even better than those of commercial $\mathrm{Pt} / \mathrm{C}$, because of their smaller particle sizes, well-defined mesopores, and higher specific surface areas. Xu et al. [76] developed a facile double-phase encapsulation approach (DPEA) to uniformly introduce thiourea and $\mathrm{CoCl}_{2}$ into the pores of MIL-101- $\mathrm{NH}_{2}$ (Al) (2-aminoterephthalate acid \& $\mathrm{Al}^{3+}$ ). Interestingly, the guests (thiourea and $\mathrm{CoCl}_{2}$ ) in the pores of MIL-101-NH2 (Al) could control the morphology of the products during pyrolysis, giving rise to a unique honeycomb-like PC nanostructure (co-doped with $\mathrm{N}$ and S) that included $\mathrm{Co}_{8} \mathrm{~S}_{9}$ nanoparticles inside. As a result, the $\mathrm{Co}_{8} \mathrm{~S}_{9} @ \mathrm{~N}$ and S-doped PC-900 (obtained at $900{ }^{\circ} \mathrm{C}$ ) exhibited high ORR activity, with an onset potential of $-0.05 \mathrm{~V}$ versus $\mathrm{Ag} / \mathrm{AgCl}$ and a half-wave potential of $-0.17 \mathrm{~V}$ versus $\mathrm{Ag} / \mathrm{AgCl}$ in alkaline media (Table 2). These values were comparable to those of $20 \mathrm{wt} \% \mathrm{Pt} / \mathrm{C}(-0.04$ and $-0.15 \mathrm{~V}$ vs. $\mathrm{Ag} / \mathrm{AgCl}$, respectively). The outstanding ORR activity originated from abundant active species $\left(\mathrm{Co}_{8} \mathrm{~S}_{9}\right.$ nanoparticles and N, S-co-doped PC) and their synergistic interactions, the unique honeycomb-like porous structure with high porosity and high surface area as well as the high degree of graphitization of PC. In addition, another common route is to post-treat MOFs with raw materials containing target elements. For example, Lou et al. [78] first post-treated ZIF-67 polyhedrons with thioacetamide, giving rise to ZIF-67@amorphous CoS yolk-shell structured polyhedrons. After pyrolysis in $\mathrm{N}_{2}$, the Co-C@Co8 $\mathrm{S}_{9}$ double-shelled nanocages (DSNCs) were achieved, containing an outer $\mathrm{Co}_{8} \mathrm{~S}_{9}$ shell and an inner carbon shell embedded with Co nanoparticles. Such well-defined DSNCs possessed comparable ORR activity to that of commercial $20 \mathrm{wt} \% \mathrm{Pt} / \mathrm{C}$ in alkaline media, and this probably was due to the unique double-shelled hollow nanostructure. Specifically, this hollow nanostructure was favorable for the exposure of active sites and allowed for the fast mass diffusion of reactants. In addition, the outer $\mathrm{Co}_{8} \mathrm{~S}_{9}$ shells, although they did not act as the primary active species, could protect the inner active Co-C shells against aggregation and leaching during the ORR processes.

Interestingly, in our other studies that also used MOFs as platforms, the preliminary results indicated that some inactive metal species such as Zn- or Sr-based inorganic nano- (or micro-) structures/PC composites also exert positive effects on ORR or OER activity of composites. However, their intrinsic activity is poor. Such positive effects are generally indirect. For instance, in one study, we prepared a bimetal MOF containing $\mathrm{Zn}$ and $\mathrm{Co}$ as precursors and annealed it at different pyrolysis temperatures (Fig. 5(C-1)) [85]. The nanostructures of the obtained electrocatalysts evolved with changing pyrolysis temperature. Generally, ZnO-Co hybrid nanoparticles embedded in $\mathrm{N}$-doped PC were achieved at 600 and $700{ }^{\circ} \mathrm{C}$, whereas CoO-Co hybrid nanoparticles dispersed in N-doped PC were obtained at
800 and $900{ }^{\circ} \mathrm{C}$. The optimized one obtained at $700{ }^{\circ} \mathrm{C}$ (i.e., CoZn-NC-700) had well-defined nanostructures (Figs. 5(C-2)-5(C-4)) and showed high ORR and OER bifunctional activity in alkaline electrolytes, even better than that of commercial $20 \mathrm{wt} . \% \mathrm{Pt} / \mathrm{C}$ (for ORR) and $\mathrm{IrO}_{2}$ (for OER), as indicated in Figs. 5(C-5) and 5(C-6). Furthermore, CoZn-NC-700 also had higher $\mathrm{Zn}$-air battery performance than the mixture of $20 \mathrm{wt} \%$ $\mathrm{Pt} / \mathrm{C}$ and $\mathrm{IrO}_{2}$. Our results demonstrated the inactive $\mathrm{Zn}$ species played positive roles in developing the bifunctional oxygen electrocatalysts as follows. (1) When the MOF precursors contained $\mathrm{Zn}$, the surface contents of active sites for both ORR (pyridinic N) and OER (Co- $\mathrm{N}_{\mathrm{x}}$ and $\mathrm{Co}^{3+}$ ) could be enhanced. (2) The initial $\mathrm{Zn}$ in the MOF precursors help the electrocatalysts to achieve high specific areas and high porosity, which is favorable for the exposure of active sites and mass transport during the electrocatalytic processes. (3) The synergistic effects between $\mathrm{Zn}$ - and Co-based precursors promoted the growth of multiwalled CNTs at high pyrolysis temperatures $\left(\geq 700{ }^{\circ} \mathrm{C}\right)$, which is favorable for charge transfer during the ORR and OER processes. In another study, another bimetal MOF precursor containing $\mathrm{Co}$ and $\mathrm{Sr}$ was synthesized via a simple reflux method (Fig. 5(D-1)) [86]. During pyrolysis in $\mathrm{N}_{2}$, Co nodes were reduced to metallic Co nanoparticles, and Sr nodes were transformed to $\mathrm{SrCO}_{3}$ nanorods, as indicated in Fig. 5(D-2). Finally, $\mathrm{Co}-\mathrm{SrCO}_{3} / \mathrm{NCs}$ were obtained at different pyrolysis temperatures, which included inner inorganic nanostructures (Co nanoparticles and $\mathrm{SrCO}_{3}$ nanorods) and outer NC shells. Among them, $\mathrm{Co}_{-} \mathrm{SrCO}_{3} / \mathrm{NC}-600$ outperformed the ones prepared at 500 and $700{ }^{\circ} \mathrm{C}$ in both activity and durability during the ORR processes in alkaline media. Moreover, the ORR activity was comparable to that of $20 \mathrm{wt} \% \mathrm{Pt} / \mathrm{C}$ (Fig. 5(D-3)). Furthermore, $\mathrm{Co}-\mathrm{SrCO}_{3} / \mathrm{NC}-600$ also afforded the optimized Zn-air battery performance among the prepared electrocatalysts, and the performance was similar to that of the battery with $20 \mathrm{wt} \%$ $\mathrm{Pt} / \mathrm{C}$. Through further investigation, we explored the positive effects from $\mathrm{SrCO}_{3}$ nanorods. Specifically, the surface $\mathrm{SrO}$ of $\mathrm{SrCO}_{3}$ nanorods enhanced charge transfer during the ORR process. The surface $\mathrm{SrO}$ could also enhance negative charges distributed on the outer NC shells, originating from the Mott-Schottky effects, thus giving rise to improved ORR selectivity and durability.

In short, according to these studies, MOFs show great potential in the development of inorganic nano- (or micro-) structures/PC composites as highly efficient oxygen electrocatalysts. The structures and the electrocatalytic performance of the resultant composites can be easily tailored by tuning the structures and compositions of the MOF-based precursors.

\section{2. $\quad$ Pure PCs (Category II)}

Still in nonoxidative atmospheres, pure PCs could be directly derived from some MOFs containing $\mathrm{Zn}$ [87-89] or other MOFs via post-treatments [90,91]. Among various MOFs, Zn-based MOFs are still the preferred choice by most researchers, because $\mathrm{Zn}$ is easily removed during pyrolysis at high temperatures $\left(>800{ }^{\circ} \mathrm{C}\right)$, mainly because of its low melting point $\left(\sim 420^{\circ} \mathrm{C}\right)$ and boiling point $\left(\sim 907^{\circ} \mathrm{C}\right)[92,93]$. In other words, 
the synthesis of pure PCs directly derived from Zn-based MOFs requires no additional post-treatments to remove metal species. It is a facile and low-cost route to pure PCs. Furthermore, to achieve high activity toward ORR and OER, various hetero-atoms (such as N, S, P, B) are usually introduced into PCs. In theory and in practice, the doped hetero-atoms can endow active sites [94-96], enhance electron conductivity [97], or result in some favorable defects [12,98], thus forming modified electronic structures and surface features of PCs for ORR or OER [97]. To derive the hetero-atom-doped PCs from MOFs, two primary synthetic protocols are used: selecting organic linkers that contain those hetero-atoms $[99,100]$ or introducing exotic hetero-atoms from various precursors [101,102]. As a result, the single-hetero-atom [103-107] and multi-hetero-atom doped PCs [100,102,108-110] can be obtained. In the following discussion, some typical examples are highlighted.

Wen et al. [106] developed N-doped meso-PCs using a mixture of Zn-MOF-74 and melamine as a precursor (Fig. 6(A)). Although Zn-MOF-74 is an oxygen-rich MOF without N, the abundant oxygen in it would be favorable for the formation of large pores during pyrolysis. The results also confirmed that large pores (9.3-12.7 nm) were formed in the resultant $\mathrm{N}$-doped PC (i.e., NPC) annealed at $1000{ }^{\circ} \mathrm{C}$ in $\mathrm{Ar}$ (denoted as NPC-1000) (Fig. 6(B)), which are favorable for the mass transport of reactants during electrocatalysis. Notably, the ORR activity evaluation showed that the NPC-1000 had high ORR activity not only in alkaline electrolyte but also in neutral and acidic media (Table 2 and Figs. 6(C)-6(E)). These values were greater or comparable to that of the benchmarked Pt/C. The results of experiments and DFT calculations demonstrated that the doped $\mathrm{N}$ with zigzag edge structure in the NPC was favorable for ORR processes. Collectively, the large mesopores and the favorable structures of the doped $\mathrm{N}$ play the key roles in ORR activity of the as-prepared NPC within a wide range of $\mathrm{pH}$ values.

In addition to doping with a single hetero-atom, doping with multi-hetero-atoms in MOF-derived PCs is also a promising route to develop highly active oxygen electrocatalysts. Zhao et al. constructed a Zn-based MOF (i.e., MC-BIF-1S), using imidazole, tetrakis(1-imidazolyl) borate and 1,4-benzenebicarboxlate as multiple organic linkers [100]. After carbonization in $\mathrm{H}_{2} / \mathrm{Ar}$, the B (from tetrakis(1-imidazolyl) borate) and N [from imidazole and tetrakis(1-imidazolyl) borate]-co-doped PCs (BNPCs) were successfully obtained. Among the BNPCs prepared at different temperatures, the BNPC- 1100 prepared at $1100{ }^{\circ} \mathrm{C}$ showed optimized bifunctional activity toward both ORR and OER in alkaline electrolytes (Table 2). More important, it also outperformed the non-co-doped PCs, including the N-doped PC derived from ZIF-8 and the B-doped PC obtained from COF-5. This performance was attributed to the positive effects of co-doping with B and N. Note, however, that the organic linkers of MOFs usually contain limited elements. To realize doping with multi-hetero-atoms in MOF-derived PCs, the introduction of more kinds of hetero-atoms from various raw materials to MOF-derived PCs or MOFs precursors is a feasible protocol. Yu et al. [108] used ultrathin Te nanowires as a template to direct the formation of Te@ZIF-8 nanofibers (Fig. 6(F)). After pyroly- sis in $\mathrm{N}_{2}$ at $1000{ }^{\circ} \mathrm{C}$, the $\mathrm{N}$-doped PC nanofibers (denoted as Z8-Te-1000) with high surface area $\left(2270 \mathrm{~m}^{2} \mathrm{~g}^{-1}\right)$ and large pore volume (2.93 $\left.\mathrm{cm}^{3} \mathrm{~g}^{-1}\right)$ were obtained (Fig. 6(G)), showing high ORR activity in alkaline media (Table 2 and Fig. 6(H)). To further enhance ORR activity, the Z8-Te-1000 was doped with a small amount of P. Remarkably, the resultant N- and P-doped PC nanofibers (i.e., P-Z8-Te-1000) exhibited enhanced activity, as compared with Z8-Te-1000. In fact, the activity was superior to that of commercial Pt/C (Fig. 6(H)). The two studies discussed earlier indicated that doping with dual hetero-atoms in PCs has advantages over doping with a single hetero-atom, and this result has been observed in other studies [111,112]. In addition, Dai et al. [102] successfully doped MOF-derived PCs with N, P, S-ternary hetero-atoms. As indicated in Fig. 6(I), MOF-5 was first encapsulated with dicyandiamide (DCDA) as the $\mathrm{N}$ source, triphenylphosphane (TPP) as the P source, and dimethyl sulfoxide (DMSO) as the S source. After pyrolysis in $\mathrm{N}_{2}$, the N, P, S-ternary-doped PCs (i.e., PNS-C-MOF-5) were achieved (Fig. 6(J)). Further evaluation of ORR activity demonstrated the activity of PNS-C-MOF- 5 was superior to that of the non-doped C-MOF-5, N-doped N-MOF-5 (only using DCDA as N source), dual-doped NS-C-MOF-5 (only using DCDA and DMSO as $\mathrm{N}$ and $\mathrm{S}$ sources, respectively), and NP-C-MOF-5 (using only DCDA and TPP as N and P sources, respectively) in alkaline media (Fig. 6(K)). These results were comparable to that of commercial Pt/C. Recently, Chen et al. [110] successfully developed a quaternary-doped PCs by utilizing ZIF-8/polymeric nanofiber three-dimensional (3D) network as a hybrid precursor. The novel hybrid precursor was constructed via the outer ZIF-8 nanoparticle layers and the inner polymeric nanofiber network (Fig. 6(L)). Actually, the polymeric nanofiber network, which included a poly(ethylene glycol) (PEG) shell and a cross-linked poly(4-vinylpyridine) (P4VP, positively charged) core, played crucial roles in the homogeneous adsorption of $\mathrm{B}_{4} \mathrm{O}_{7}{ }^{2-}, \mathrm{HPO}_{4}{ }^{2-}$, and $\mathrm{SO}_{4}{ }^{2-}$ as $\mathrm{B}, \mathrm{P}, \mathrm{S}$ sources, respectively. This was primarily because of the abundant hierarchical pores in the polymeric network and the strong electrostatic attraction between the positive charged P4VP core with homogeneously dispersed 4VP units and those anions. The pores of the outer ZIF-8 were too small to contain the large anions mentioned earlier, however. As a result, the PC nanofiber network was obtained after carbonization, which was homogeneously quaternary-doped with $\mathrm{N}$ (from ZIF-8 and the pyridine units of P4VP core), B, P, and S (Fig. 6(M)). Similar to PNS-C-MOF-5 [102], the quaternary-doped PC had higher ORR activity than the controlled single $(\mathrm{N})$, dual (NP, NB, and NS) and ternary (NPS, NBS, and NBP)-doped PCs in alkaline electrolytes (Fig. 6(N)). In addition, the quaternary-doped PC was comparable to that of commercial $\mathrm{Pt} / \mathrm{C}$, and this was mainly attributed to the strong synergistic effects of the doped multi-hetero-atoms.

In short, these studies have demonstrated that MOFs, especially $\mathrm{Zn}$-based MOFs, can directly serve as precursors or be modified with raw materials containing various exotic hetero-atoms. The resultant doped hetero-atoms (especially multi-hetero-atoms) in the derived PCs, are beneficial for ORR or OER processes. 
(A)

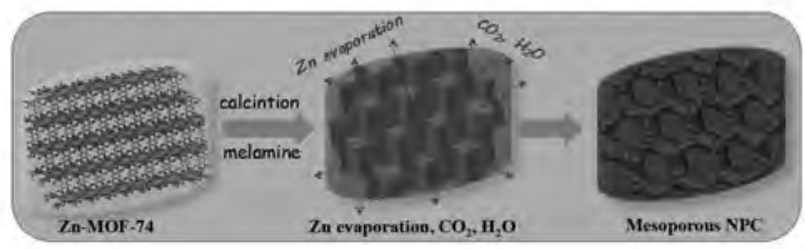

(C)

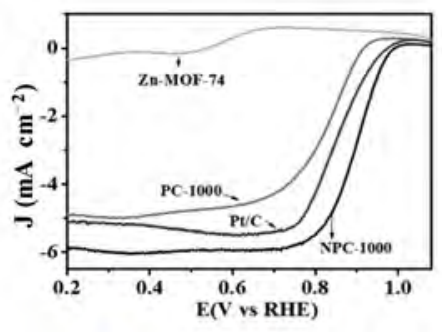

(F)

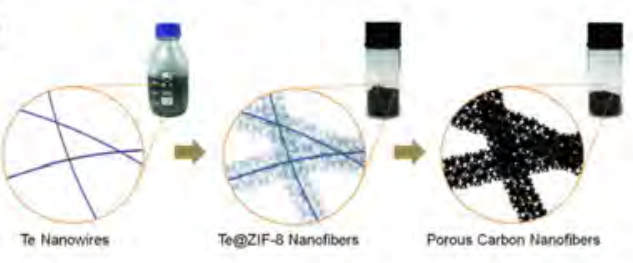

(D)
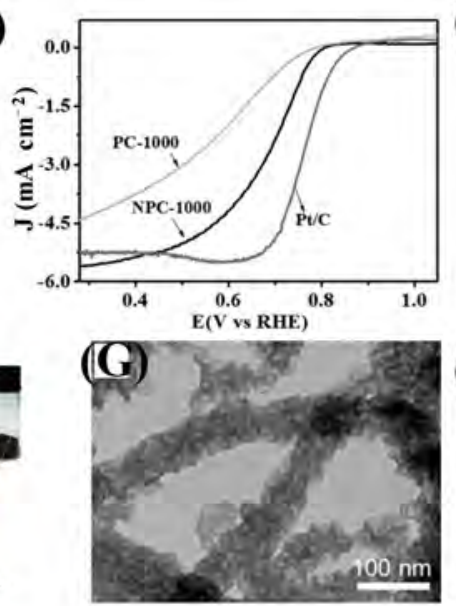

(I)

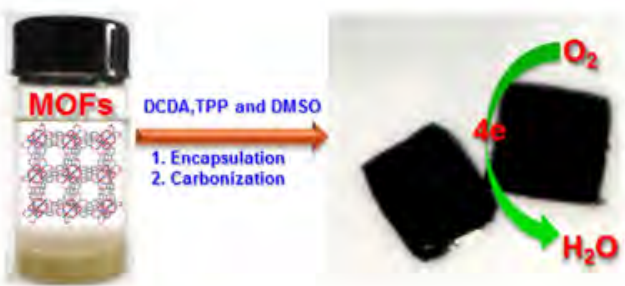

(L)

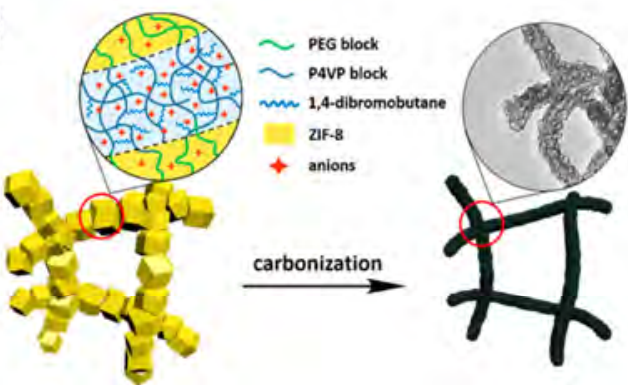

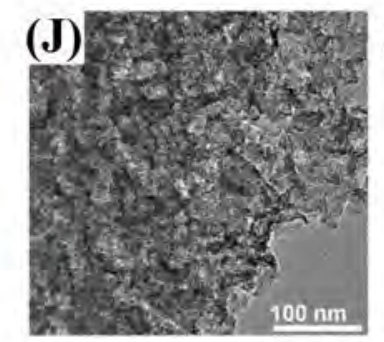

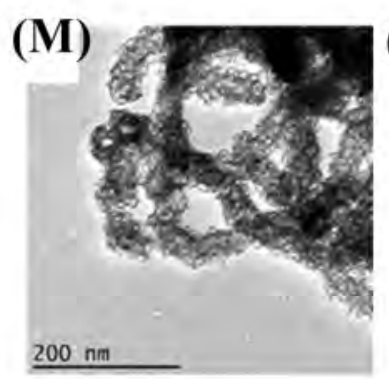

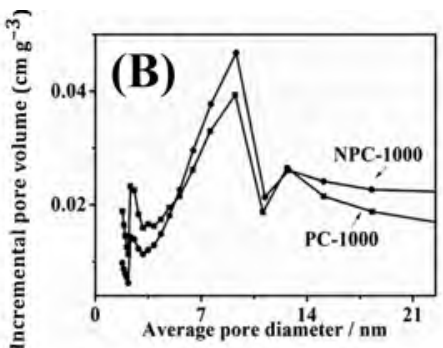

(E)

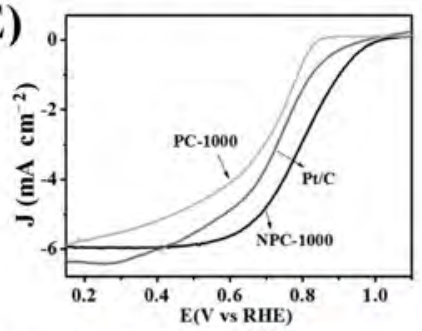

(H)

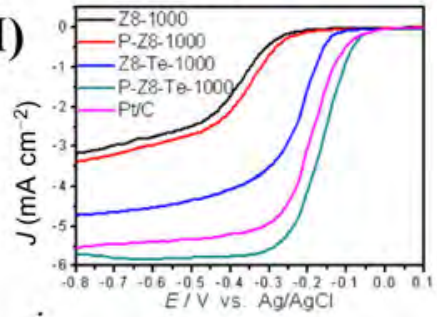

(K)

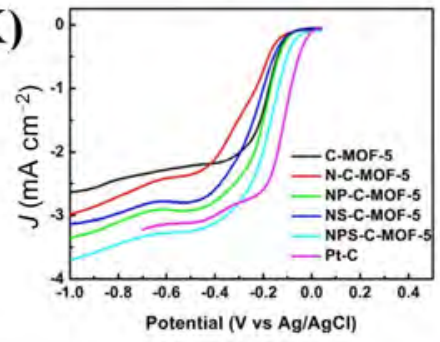

(N)

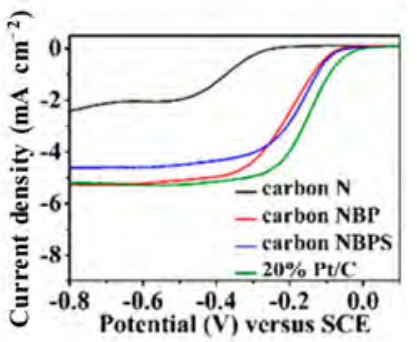

Fig. 6. (A) Illustration of the preparation of N-doped PC, (B) pore size distribution of NPC-1000 and PC-1000, (C) ORR polarization curves of Zn-MOF-74, NPC-1000, PC-1000 and Pt/C in $\mathrm{O}_{2}$-saturated $0.1 \mathrm{~mol} / \mathrm{L} \mathrm{KOH,} \mathrm{(D)} \mathrm{ORR} \mathrm{polarization} \mathrm{curves} \mathrm{of} \mathrm{NPC-1000,} \mathrm{PC-1000} \mathrm{and} \mathrm{Pt/C} \mathrm{in}$ $\mathrm{O}_{2}$-saturated $0.5 \mathrm{~mol} / \mathrm{L} \mathrm{H}_{2} \mathrm{SO}_{4}$, and (E) ORR polarization curves of NPC-1000, PC-1000 and Pt/C in $\mathrm{O}_{2}$-saturated $0.1 \mathrm{~mol} / \mathrm{L}$ phosphate buffer solution $(\mathrm{pH}=7.0)$. Reproduced with permission from Ref. [106], Copyright 2017 WILEY-VCH. (F) Illusration of the synthesis of PC nanofibers, (G) TEM image of Z8-Te-1000 and (H) ORR polarization curves of the prepared electrocatalysts at $1000^{\circ} \mathrm{C}$ and $\mathrm{Pt} / \mathrm{C}$ in $\mathrm{O}_{2}$-saturated $0.1 \mathrm{~mol} / \mathrm{L} \mathrm{KOH}$. Reproduced with permission from Ref. [108], Copyright 2014 American Chemistry Society. (I) Illustration of the preparation of NPS-C-MOF-5, (J) TEM image of NPS-C-MOF-5 and (K) ORR polarization curves of the various prepared electrocatalysts and Pt/C in $\mathrm{O}_{2}$-saturated $0.1 \mathrm{~mol} / \mathrm{L} \mathrm{KOH}$. Reproduced with permission from Ref. [102], Copyright 2014 Nature Publishing Group. (L) Illustration of the synthesis of multi-hetero-atom doped PC nanofiber network, (M) TEM image of N, B, P, S-doped PC nanofiber network, and (N) ORR polarization curves of the PC nanofiber network doped with different hetero-atoms and $\mathrm{Pt} / \mathrm{C}$ in $\mathrm{O}_{2}$-saturated $0.1 \mathrm{~mol} / \mathrm{L} \mathrm{KOH}$. Reproduced with permission from Ref. [110], Copyright 2017 American Chemistry Society. The ORR polarization curves were all collected at $1600 \mathrm{rpm}$ with a sweep rate of $10 \mathrm{mV} \mathrm{s}^{-1}$.

\subsection{Pure inorganic nano- (or micro-) structured materials (Category III)}

If an MOF is post-treated in an oxidative atmosphere (commonly in air or $\mathrm{O}_{2}$ ) or with some reactants containing $\mathrm{S}, \mathrm{Se}, \mathrm{P}, \mathrm{B}$, and $\mathrm{N}$, it can be converted into pure inorganic materials with various nano- (or micro-) structures. These structures can act 
as highly efficient oxygen electrocatalysts for ORR or OER, including oxides [113-115], sulfides [116], selenides [117,118], phosphides [119], and nanocomposites [120].

Many recently developed inorganic porous materials derived from various MOFs mainly have been applied as OER electrocatalysts (Table 2). In a recent report, Lou's group [113] first synthesized Ni-Co bimetallic PBA cubic nanocages via anisotropic etching. After annealing in air, Ni-Co mixed oxide nanocages, with the retained nanostructures of the PBA cubic nanocages, were formed (Fig. 7(A) and 7(B)). Their OER activities in alkaline media were superior to some common porous cubes. This was attributed to their complex cage-like porous and hollow nanostructures, which ware beneficial for electrolyte access to the active sites. In addition, the porous and hollow metal chalcogenides and phosphides can be derived from MOFs. Some Co-based MOF starting materials were post-treated to $\mathrm{Co}_{3} \mathrm{~S}_{4} @ \mathrm{MoS}_{2}$ hollow heterostructures (Fig. 7(C) and 7(D)) [116], CoSe2 hollow microspheres (Fig. 7(E) and 7(F)) [117], and CoP hollow polyhedrons (Fig. 7(G) and 7(H])) [119]. These porous and hollow metal chalcogenides and phosphides exhibited promising OER activity, with low $E_{j}=10$ values and low Tafel slopes in alkaline electrolytes (Table 2). These materials benefited from the full exposure of active sites to the electrolytes, fast mass, and high charge transfer efficiency because of their high porosity hollow nano- (or micro-) structures.

Recently, 3D nano- (or micro-) structures grown on current collectors displayed high performance for gas evolution reactions (such as oxygen evolution and hydrogen evolution) because of their high conductivity, full exposure of active sites to electrolytes, and high gas release efficiency [121-124]. Dou et al. [120] first deposited cobalt carbonate hydroxide (CCH) nanowire arrays on $\mathrm{Ni}$ substrates. Then, the $\mathrm{CCH}$ nanowires were coated with ZIF-67 layers, forming 3D hierarchically structured CCH@ZIF-67 nanowire arrays. After phosphorization, the 3D hierarchically structured $\mathrm{Co}_{3} \mathrm{O}_{4} @ \mathrm{CoP}$ was achieved (Figs. 7(I) and 7(J)). This hierarchical structure on Ni substrates, which had high conductivity, abundant exposed active sites, and short diffusion paths for electrolytes, had an exceptionally low $E_{j=10}$ value (1.47 V vs. RHE) and low Tafel slope of $51.4 \mathrm{mV} \mathrm{dec}^{-1}$ in $1 \mathrm{~mol} / \mathrm{L} \mathrm{KOH}$, as well as excellent durability.

These studies have demonstrated that MOFs, because of their intrinsic porosity, tunable compositions, and pore structures, are considered excellent precursors or templates to easily prepare various pure inorganic electrocatalysts with well-defined porous and complex nano- (micro-) structures. It remains challenging, however, for some conventional synthetic methods to achieve the porous and complex nano- (micro-) structures, further suggesting the advantages of conversion protocols.

\subsection{Single-atom electrocatalysts (Category IV)}

In recent years, single-atom (metal atoms) electrocatalysts have been emerging rapidly. Simply speaking, the single-atom electrocatalysts can be defined as catalysts with atomically dispersed active metal atoms on their supports. These materi-
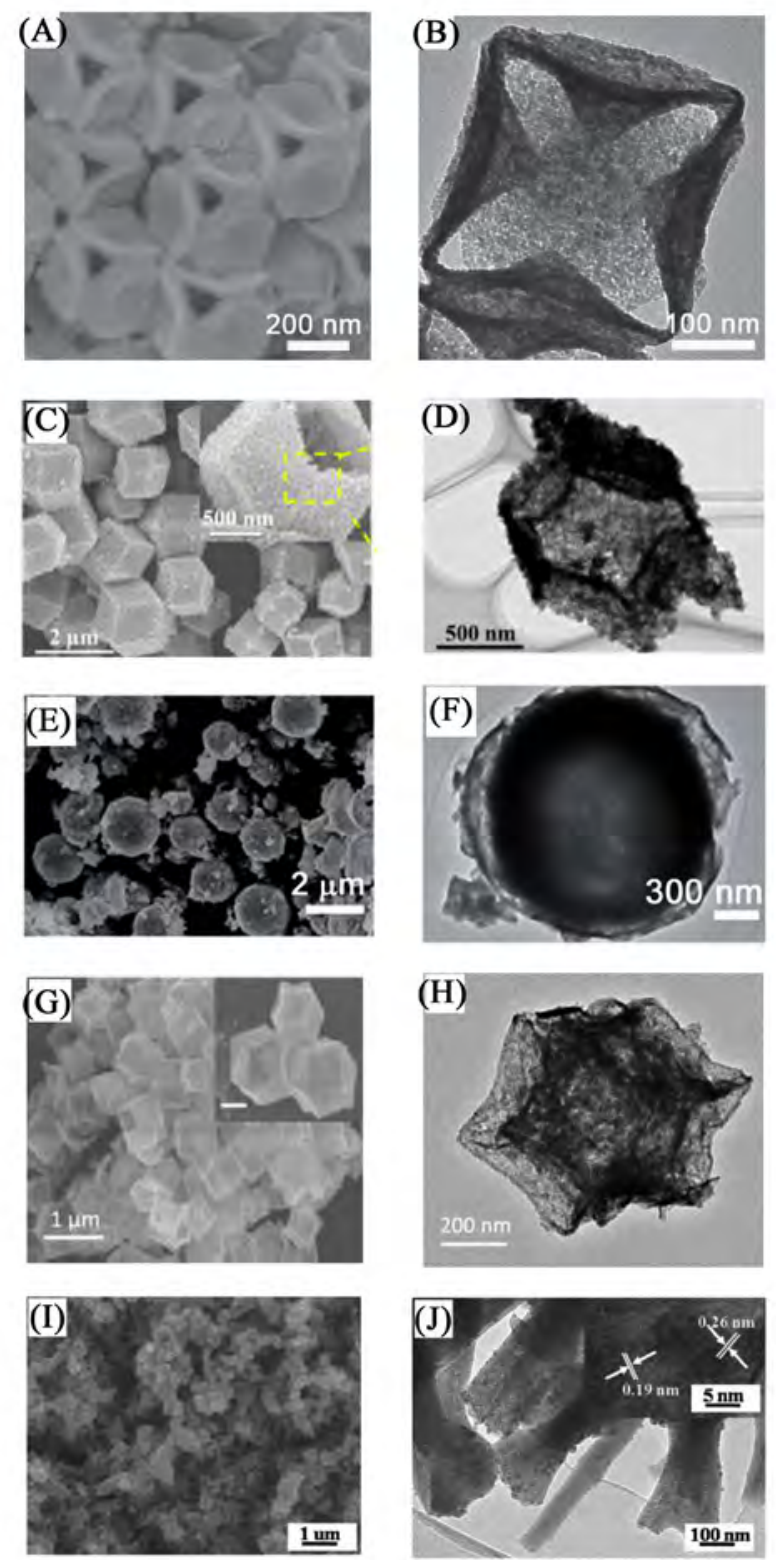

Fig. 7. SEM (A) and TEM (B) images of Ni-Co mixed oxide cages. Reproduced with permission from Ref. [113], Copyright 2016 WILEY-VCH SEM (C) and TEM (D) images of hollow $\mathrm{Co}_{3} \mathrm{~S}_{4} @ \mathrm{MoS}_{2}$ heterostructures. Reproduced with permission from Ref. [116], Copyright 2017 American Chemistry Society. (E) and (F) show SEM and TEM images of hollow $\mathrm{CoSe}_{2}$ microspheres, respectively. Reproduced with permission from Ref. [117], Copyright 2017 Royal Society of Chemistry. SEM (G) and TEM (H) images of CoP hollow polyhedrons. Reproduced with permission from Ref. [119], Copyright 2016 American Chemistry Society. SEM (I) and TEM (J) images of hierarchically structured $\mathrm{Co}_{3} \mathrm{O}_{4} @ \mathrm{CoP}$. Reproduced with permission from Ref. [120], Copyright 2017 WILEY-VCH.

als are attracting more attention because they have unique features, such as homogeneously dispersed active sites, high selectivity, extremely high atom utilization efficiency (nearly $100 \%)$, and strong interaction between atomic active sites and supports that can enhance the catalytic performance. These features are different from those of conventional nanoparticles-based electrocatalysts $[125,126]$. However, the great chal- 
lenge of developing single-atom electrocatalysts is the formation of highly isolated active metal atoms on supports (rather than nanoparticles) with high productivity. In spite of this great challenge, the general strategies for producing single-atom electrocatalysts are to optimize the precursors and the supports as well as precisely control the synthetic procedures [125]. On the basis of these strategies, some electrocatalysts for ORR and OER, with high electrocatalytic performance, have been developed recently via using appropriate MOFs as precursors or controlling the post-treatments.

$\mathrm{Li}$ et al. selected Zn-MOFs as the platform to successfully obtain Co single atoms/N-doped PC (Co SAs/N-C) [93] and isolated single-atom Fe/N-doped PC (Fe-ISAs/CN) [127] via the pyrolysis of $\mathrm{Zn} / \mathrm{Co}$ bimetallic MOF (i.e., $\mathrm{ZIF}(\mathrm{Zn} / \mathrm{Co}$ ) that is isostructural with the typical ZIF-8 (Zn) or ZIF-67 (Co)) and Fe-doped ZIF-8, respectively. The crucial factor for achieving those single-atom electrocatalysts is the unique structure of Zn-MOFs containing Co or Fe sites. In Zn/Co bimetallic MOF with the proper ratios of $\mathrm{Zn}$ and Co [93], Co sites can be highly isolated by $\mathrm{Zn}$ sites in all dimensions, resulting in a relatively large distance between the adjacent Co sites. During pyrolysis in $\mathrm{N}_{2}, \mathrm{Zn}$ atoms were evaporated at high temperatures $(>800$ ${ }^{\circ} \mathrm{C}$ ), while the formed $\mathrm{N}$ sites originating from the organic linker (2-methylimidazole) can stabilize Co sites to prevent the formation of Co-Co bonds (i.e., Co nanoparticles) between the adjacent Co sites (Fig. 8(A)). As a result, single Co atoms could anchor on $\mathrm{N}$-doped PC with a planar active Co- $\mathrm{N}_{4}$ structure at $800{ }^{\circ} \mathrm{C}$ or as $\mathrm{Co}-\mathrm{N}_{2}$ formed at $900{ }^{\circ} \mathrm{C}$, which was dispersed over the PC support (Fig. 8(B)). As shown in Fig. 8(C), the Co SAs/N-C-900, with the highly active Co- $\mathrm{N}_{2}$ structure, showed superior ORR activity to commercial Pt/C, Co SAs/N-C-800 and the Co nanoparticles-based counterpart (prepared at $900{ }^{\circ} \mathrm{C}$ using Co-MOF) in alkaline electrolyte. In another Zn-MOF (i.e., Fe-doped ZIF-8), the single Fe(acac) 3 (as Fe precursor) molecule can be trapped in a single cage of ZIF-8, expanding the distance of the adjacent $\mathrm{Fe}(\mathrm{acac})_{3}$ molecules (Fig. 8(D)). After pyrolysis in Ar, the remaining Fe atoms can be stabilized by the formed $\mathrm{N}$ sites and widely distributed on the PC support (Fig. 8(E)). Among the resultant Fe-ISAs/CN materials, Fe-ISAs/CN-900 had the most dispersed active Fe-N 4 structure, with a high loading of $\sim 2.16 \mathrm{wt} \%$. As a result, it had excellent ORR activity in alkaline media (Fig. 8(F)). Notably, in addition to selecting ZIF-8 as the host for Fe(acac) 3 molecules, the control experiments demonstrated that the feeding amount of $\mathrm{Fe}(\mathrm{acac})_{3}$ was also important to obtain Fe-ISAs/CN. In another similar work, Wu et al. [128] also utilized ZIF-8 to host Fe pre-
(A)
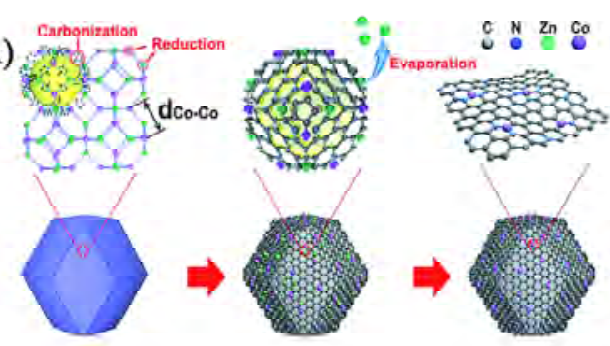

(D)

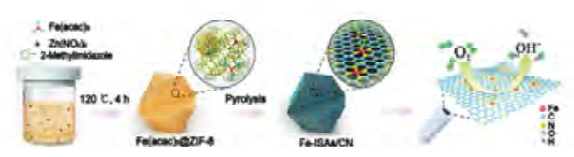

(G)

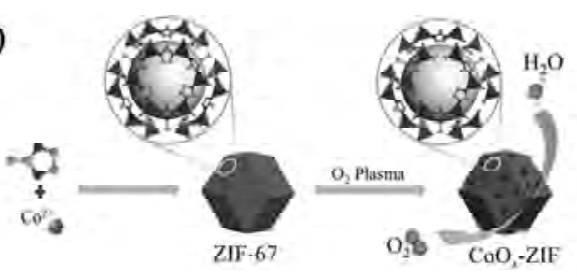

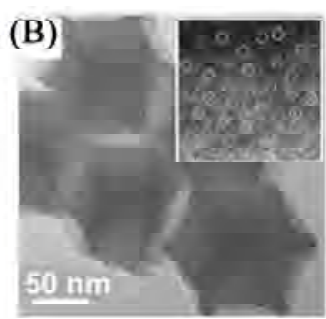

(C)
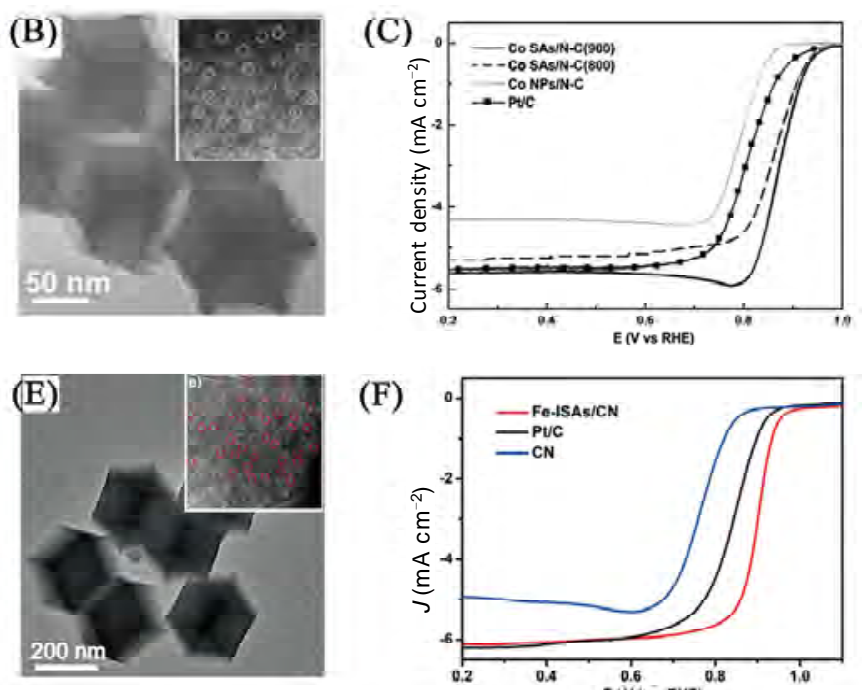

(F)
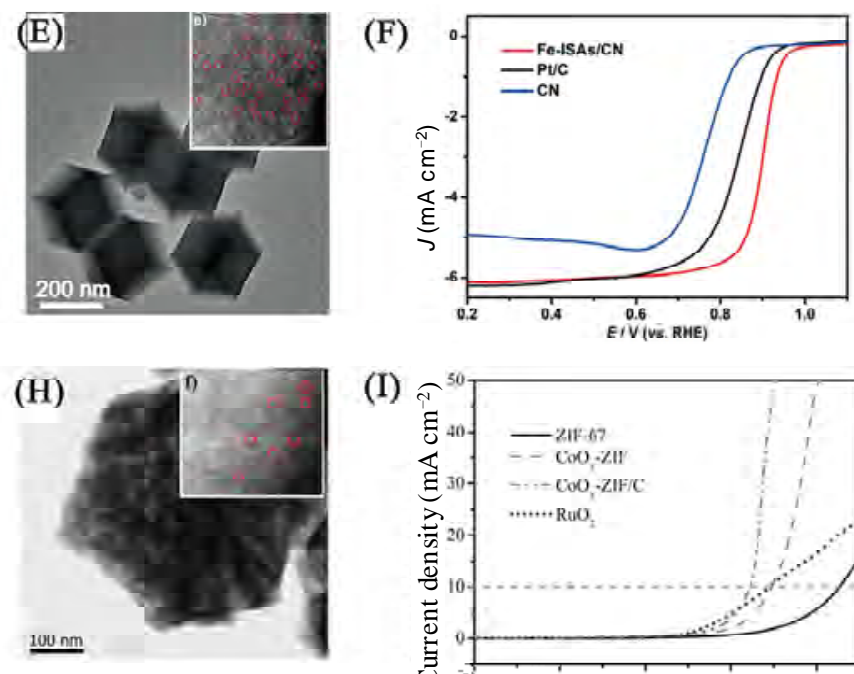

(I)

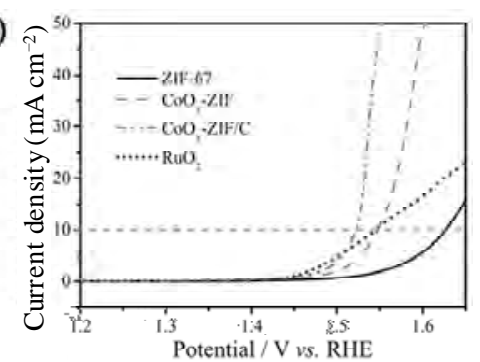

Fig. 8. (A) Illustration of the formation of Co SAs/N-C; (B) TEM and HAADF-STEM (inset) images of Co SAs/N-C; (C) ORR polarization curves of Co $\mathrm{SAs} / \mathrm{N}-\mathrm{C}$, Co NPs/N-C and Pt/C in $\mathrm{O}_{2}$-saturated $0.1 \mathrm{~mol} / \mathrm{L} \mathrm{KOH}$ at $1600 \mathrm{rpm}$ with a sweep rate of $10 \mathrm{mV} \mathrm{s}^{-1}$. Reproduced with permission from Ref. [93], Copyright 2016 WILEY-VCH. (D) Illustration of the formation of Fe-ISAs/CN; (E) TEM and HAADF-STEM (inset) images of Fe-ISAs/CN; (F) ORR polarization curves of Fe-ISAs/CN, CN and Pt/C in $\mathrm{O}_{2}$-saturated $0.1 \mathrm{~mol} / \mathrm{L} \mathrm{KOH}$ at $1600 \mathrm{rpm}$ with a sweep rate of $10 \mathrm{mV} \mathrm{s}^{-1}$. Reproduced with permission from Ref. [127], Copyright 2017 WILEY-VCH. (G) Illustration of the preparation of $\mathrm{CoO}_{x}$-ZIF-67; (H) TEM and HAADF-STEM (inset) images of $\mathrm{CoO}_{x}$-ZIF-67; (I) OER polarization curves of $\mathrm{CoO}_{x}$-ZIF-67, $\mathrm{CoO}_{x}$-ZIF-67/C, ZIF-67 and $\mathrm{RuO}_{2}$ in $\mathrm{O}_{2}$-saturated 1 mol/L KOH. Reproduced with permission from Ref. [129], Copyright 2017 WILEY-VCH. 
cursor as Fe-doped ZIF-8 for single atom Fe/N-doped PC. In the framework of this Fe-doped ZIF-8, $\mathrm{Fe}^{3+}$ partially replaced $\mathrm{Zn}^{2+}$ and coordinated with 2-methylimidazole probably in the form of Fe- $\mathrm{N}_{4}$. This structure was different from the structure of the former Fe-doped ZIF-8 [127]. The single atom Fe/N-doped PC exhibited high ORR activity with a positive $E_{1 / 2}$ value of $0.850 \mathrm{~V}$ versus RHE (Table 2) in $0.5 \mathrm{~mol} / \mathrm{L}_{2} \mathrm{SO}_{4}$, and this likely was due to the homogenously dispersed $\mathrm{Fe}-\mathrm{N}_{4}$ active sites. Accordingly, Zn-based MOFs are considered to be excellent platforms for achieving single-atom electrocatalysts.

In addition to using the proper MOF precursors, advanced post-treatment techniques are highly required to obtain single-atom electrocatalysts. Recently, Wang et al. [129] developed a post-treatment technique using $\mathrm{O}_{2}$ plasma to rapidly post-treat ZIF-67 (Fig. 8(G)). This highly efficient post-treatment is beneficial for forming atomic-scale $\mathrm{CoO}_{x}$ species in ZIF-67 (Fig. 8(H)), while still preserving the main structure of the pure ZIF-67. The results demonstrated that the atomically dispersed $\mathrm{CoO}_{x}$ in ZIF-67 could greatly enhance the OER activity of ZIF-67. Thus, in $1 \mathrm{~mol} / \mathrm{L} \mathrm{KOH}, \mathrm{CoO}_{x}$-ZIF-67 required low potential (i.e., $E_{j=10}=1.548 \mathrm{~V}$ vs. RHE) to reach a current density of $10 \mathrm{~mA} \mathrm{~cm}^{-2}$, which is comparable to that of commercial $\mathrm{RuO}_{2}$ (Fig. 8(I)). However, the $E_{j}=10$ value of the pure ZIF-67 was as high as $1.63 \mathrm{~V}$ versus RHE, showing inferior OER activity to $\mathrm{CoO}_{x}$-ZIF-67. This pioneer work opened a new door to directly activate MOFs via plasma post-treatment techniques.

In short, although there are great challenges to obtain single-atom electrocatalysts, MOFs offer a relatively easy way to do so. However, the synthesis of MOF-based single-atom electrocatalysts is in its infancy. More efforts are required to make this conversion protocol from MOFs more reliable for practical applications.

According to the studies reported in this subsection, MOFs with diverse compositions and structures are excellent platforms or precursors to easily achieve derived oxygen electrocatalysts with desired electrocatalytic properties. Generally speaking, these derived electrocatalysts have well-defined complex structures and tunable compositions, which are favorable for increasing the number of active sites and boosting intrinsic activity. It remains challenging, however, for some conventional synthetic methods to realize similar structures, compositions, and electrocatalytic performance. Thus, this protocol of using MOFs as platforms or precursors is promising to develop highly efficient oxygen electrocatalysts for energy storage and conversion techniques.

\section{Conclusions and outlook}

In conclusion, ORR and OER are crucial to some energy storage and conversion techniques, such as fuel cells and metal-air batteries. They suffer, however from sluggish reaction kinetics. Thus, it is urgent to develop highly efficient oxygen electrocatalysts toward ORR and OER with low-cost and high earth-abundance (i.e., non-PGM oxygen electrocatalysts). Among the developed non-PGM oxygen electrocatalysts, MOF-based electrocatalysts have attracted increasing interest, mainly because of their distinct features of pure MOFs and their derivatives that are favorable for ORR or OER, such as high porosity, high surface areas, tunable structures, and compositions. Herein, this review discusses the recent progress in the synthesis and applications of oxygen electrocatalysis from pure MOFs and MOF-derived materials. Although many research advancements have been made to explore highly efficient MOF-based oxygen electrocatalysts, more efforts are required to increase the number of active sites, boost intrinsic activity, and achieve high activity toward ORR and OER. Several issues must be addressed in future studies.

As for pure MOF-based oxygen electrocatalysts, the persisting challenges are as follows:

(1) The long-existing issue of poor conductivity of pure MOFs. Although the incorporation of conductive materials can improve their conductivity or charge transfer efficiency during electrocatalysis, the considerable interfacial resistance between MOFs and conductive substrates persists. An alternative solution to this issue is the development of charge-conductive MOFs. Despite some recent advances, it is still challenging to design and realize highly conductive pathways in MOFs, which requires appropriate organic linkers, metal nodes, and feasible synthetic protocols.

(2) Oxygen electrocatalysis always occurs in hash conditions, such as in strong alkaline or acidic electrolytes. The stability of pure MOFs should receive more attention. The enhancement of the coordination effects between organic linkers and metal nodes plays a key role in stabilizing MOFs under those hash conditions. The utilization of N-donor linkers (e.g., metalloporphyrin) or high-valence metal ions (e.g., $\mathrm{Fe}^{3+}, \mathrm{Al}^{3+}$, $\mathrm{Cr}^{3+}$, and $\mathrm{Zr}^{4+}$ ) is considered a reliable approach $[45,130,131]$.

(3) Most MOFs have abundant micropores (pore size smaller than $2 \mathrm{~nm}$ ). Although the small micropores can result in favorable high surface areas and high loading of active sites, the lager mesopores (pore size of 2-50 nm) or even macropores (pore size larger than $50 \mathrm{~nm}$ ) are still needed to improve mass transport of reactants during oxygen electrocatalysis. Accordingly, MOFs with hierarchical pores, which contain micropores and mesopores or macropores, are highly recommended. Even though some mesoporous MOFs have been synthesized via extending the sizes of organic linkers [132], it is still difficult to further enlarge the intrinsic pores or construct the intrinsic hierarchical pores through this protocol [133]. To realize hierarchical pores in MOFs, the additional mesopores or macropores can be created from various soft or hard templates [134].

(4) According to the discussion in the subsection of pure MOF-based materials as oxygen electrocatalysts, the active sites of MOFs for ORR and OER are associated with metal nodes, especially open or unsaturated ones. To increase the number of active sites in MOFs, more open or unsaturated metal nodes are required. However, open or unsaturated metal nodes are still limited in MOFs. In view of this defect, engineering methods for other PGM electrocatalysts can be employed to increase open or unsaturated metal nodes as active sites [135]. Another possible route to enhance the number of active sites for MOFs is to decorate them with other active species, which 
will create more opportunities for MOFs as highly efficient oxygen electrocatalysts.

As for MOF-derived oxygen electrocatalysts, several challenges are listed as follows:

(5) The use of MOFs as precursors is limited to a few well-developed MOFs, such as ZIF-8, MOF-5, ZIF-67, MOF-74, MIL-101, MIL-100, and HKUST-1. The incorporation of MOFs with other components, to form composites, would provide more available MOF-based precursors. This strategy opens more pathways to achieve highly efficient MOF-derived oxygen electrocatalysts, with more varieties of doped hetero-atoms (e.g., N, B, P, and S), more designable compositions and more well-defined porous structures from 1D to 3D. These features are favorable to improve the intrinsic activity and increase the number of active sites. At present, more effort is needed.

(6) In most of the relevant works, the conversion of MOFs into the derived oxygen electrocatalysts via pyrolysis or other treatments always results in the growth or aggregation of metal-based nanoparticles, which has negative impacts on the utilization of active metal sites. Recent advances demonstrate that single-atom electrocatalysts are ideal to make full use of active metal sites, thus greatly increasing the number of active sites and boosting intrinsic activity [125,126]. Some typical studies that used MOFs as precursors have confirmed the advantages of MOFs in preparation of single-atom electrocatalysts $[93,127,129]$. Despite these advances, the loading of active metal sites in the developed single-atom electrocatalysts is generally low, and it remains challenging to prepare single-atom electrocatalysts with high output through simple synthetic methods.

(7) According to our results $[85,86]$, some inactive species, such as $\mathrm{Zn}$ - and Sr-based ones, play positive roles in developing highly efficient oxygen electrocatalysts. However, the present preliminary experimental results do not sufficiently explain the origin of the positive effects of added inactive species. A systematic investigation should be performed in the future, which could reveal the mechanism behind these positive contributions and explore more useful inactive species.

(8) The conversion of MOFs has some disadvantages. Most frequently, the surface areas and porosity of MOF-based precursors are greatly reduced and their ordered pores are significantly altered, which may affect the mass transfer processes during oxygen electrocatalysis. In addition, although the derived electrocatalysts tend to have similar morphologies to their MOF-based precursors, it is still difficult to control the formation of active nanostructures in the derived electrocatalysts during the conversion processes. To produce derived oxygen electrocatalysts with high surface areas, high porosity, hierarchical pores, and controlled morphologies (or nanostructures), it is important to select appropriate MOFs (such as Zn-based MOFs or MOFs containing other easily removable species) as precursors and to carefully control the conversion processes. To date, the knowledge of conversion processes is still limited, and the relevant studies are rare. The investigation of conversion processes, especially for the formation of active nanostructures, should be performed in future studies via various advanced techniques, such as in situ TEM, in situ X-ray absorption fine structure, and gas chromatography-mass spectrometry. Meanwhile, conversion techniques with controlled precision should also be developed.

In addition to these specific challenges for pure MOFs or MOF-derived oxygen electrocatalysts, some general issues are also noted as follows:

(9) The nature of active sites in pure MOFs or MOF-derived oxygen electrocatalysts and the relevant electrocatalytic mechanisms of those active sites are still not fully understood. Advanced characterization techniques, especially in situ or operando techniques, as well as theoretical calculation and modeling are required to gain insight into these fundamental issues. Together with the evaluation of electrocatalytic performance, the general structure-performance relationship for MOF-based oxygen electrocatalysts can be established, and this will be beneficial for achieving more highly efficient oxygen electrocatalysts.

(10) Finally, the $\mathrm{O}_{2}$-bubble wettability of an oxygen electrocatalyst is still less concerned. During both ORR and OER processes on solid electrocatalysts, the formed triple-phase (gas-liquid-solid) interfaces are important for the electrocatalytic processes. For ORR, a stable $\mathrm{O}_{2}$ layer at the triple-phase interfaces is necessary to boost $\mathrm{O}_{2}$ diffusion and charge transfer. Thus, a superaerophilic interface is required to trap $\mathrm{O}_{2}$ bubbles effectively [136]. On the contrary, for OER, a superaerophobic interface is needed to release the formed $\mathrm{O}_{2}$ bubbles easily, to prevent the $\mathrm{O}_{2}$ bubbles from blocking the contact between the electrolyte and the surface of electrocatalysts [136]. Accordingly, there is a significant difference in the favorable $\mathrm{O}_{2}$-bubble wettability conditions between ORR and OER electrocatalysts. To further boost their oxygen electrocatalytic activity, the $\mathrm{O}_{2}$-bubble wettability of MOF-based oxygen electrocatalysts should be tailored by adjusting the nano-/micro-structures and the compositions of pure MOFs or MOF-based derivatives, in addition to increasing the number of active sites and improving intrinsic activity.

In conclusion, despite many challenges, MOFs are excellent platforms to develop highly efficient oxygen electrocatalysts for many energy storage and conversion applications. With more and more sustained efforts, MOF-based oxygen electrocatalysts will have practical applications and will one day be commercialized.

\section{References}

[1] I. Katsounaros, S. Cherevko, A. R. Zeradjanin, K. J. Mayrhofer, Angew. Chem. Int. Ed., 2014, 53, 102-121.

[2] C. Tang, H. S. Wang, H. F. Wang, Q. Zhang, G. L. Tian, J. Q. Nie, F. Wei, Adv. Mater., 2015, 27, 4516-4522.

[3] H. F. Wang, C. Tang, B. Wang, B. Q. Li, Q. Zhang, Adv. Mater., 2017, 29, 1702327.

[4] B. Q. Li, S. Y. Zhang, C. Tang, X. Y. Cui, Q. Zhang, Small, 2017, 13, 1700610.

[5] B. Q. Li, Z. J. Xia, B. Zhang, C. Tang, H. F. Wang, Q. Zhang, B. S. Zhang, Nat. Commun., 2017, 8, 934.

[6] J. F. Kong, W. L. Cheng, Chin. J. Catal., 2017, 38, 951-969.

[7] C. Du, X. H. Gao, W. Chen, Chin. J. Catal., 2016, 37, 1049-1061.

[8] C. M. Wang, S. Bai, Y. J. Xiong, Chin. J. Catal., 2015, 36, 1476-1493. 


\section{Graphical Abstract}

Chin. J. Catal., 2018, 39: 207-227 doi: 10.1016/S1872-2067(18)63017-7

Metal-organic frameworks for highly efficient oxygen electrocatalysis

Xiaobo He, Fengxiang Yin *, Hao Wang, Biaohua Chen, Guoru Li

Beijing University of Chemical Technology; Changzhou University; Beijing Key Laboratory of Energy Environmental Catalysis;

Changzhou Institute of Advanced Materials, Beijing University of Chemical Technology

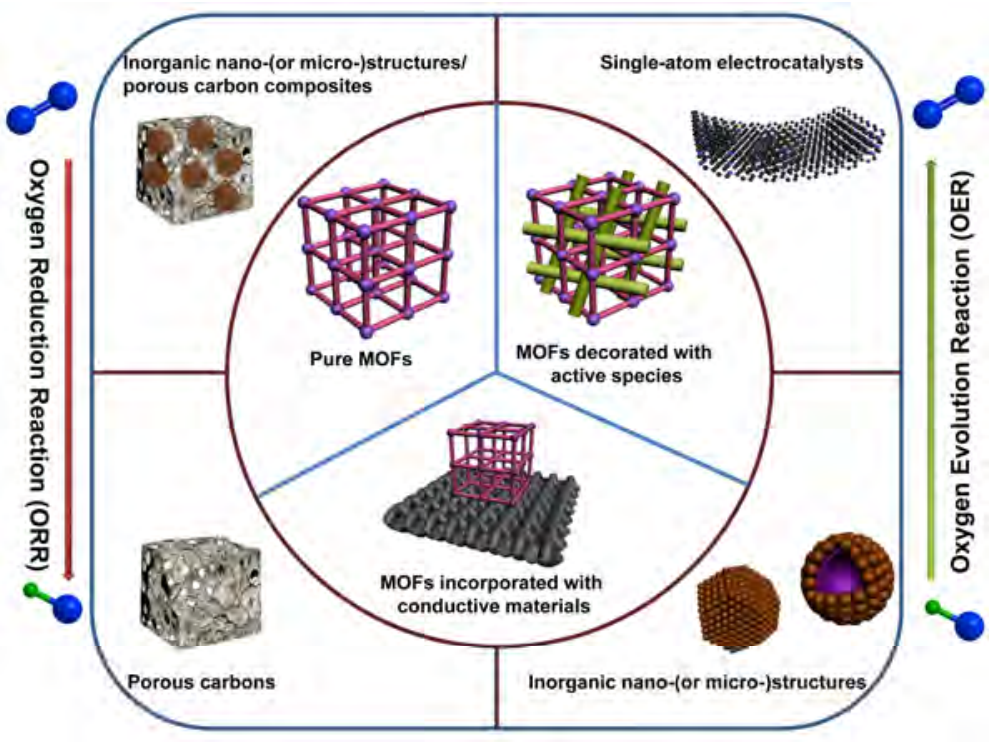

Metal-organic frameworks are highly porous crystalline materials, which are constructed by metal nodes and organic linkers. They can act as active materials for oxygen electrocatalysis or as excellent platforms to develop highly efficient oxygen electrocatalysts.

[9] L. Zhou, M. F. Shao, M. Wei, X. Duan, J. Energy Chem., 2017, 26, 1094-1106.

[10] C. Tang, M. M. Titirici, Q. Zhang, J. Energy Chem., 2017, 26, 1077-1093.

[11] S. Chen, J. J. Duan, M. Jaroniec, S. Z. Qiao, Adv. Mater., 2014, 26, 2925-2930.

[12] C. Tang, Q. Zhang, Adv. Mater., 2017, 29, 1604103.

[13] Z. W. Seh, J. Kibsgaard, C. F. Dickens, I. Chorkendorff, J. K. Nørskov, T. F. Jaramillo, Science, 2017, 355, eaad4998/1-eaad4998/12.

[14] F. Lu, M. Zhou, Y. Zhou, X. Zeng, Small, 2017, 13, 1701931.

[15] Y. J. Kang, P. D. Yang, N. M. Markovic, V. R. Stamenkovi, Nano Today, 2016, 11, 587-600.

[16] W. G. Lu, Z. W. Wei, Z. Y. Gu, T. F. Liu, J. Park, J. Park, J. Tian, M. W. Zhang, Q. Zhang, T. Gentle III, M. Bosch, H. C. Zhou, Chem. Soc. Rev., 2014, 43, 5561-5593.

[17] B. Li, H. M. Wen, Y. J. Cui, W. Zhou, G. D. Qian, B. L. Chen, Adv. Mater., 2016, 28, 8819-8860.

[18] S. M. J. Rogge, A. Bavykina, J. Hajek, H. Garcia, A. I. Olivos-Suarez, A. Sepúlveda-Escribano, A. Vimont, G. Clet, P. Bazin, F. Kapteijn, M. Daturi, E. V. Ramos-Fernandez, F. X. Llabrés i Xamena, V. Van Speybroeck, J. Gascon, Chem. Soc. Rev., 2017, 46, 3134-3184.

[19] O. M. Yaghi, M. O'Keeffe, N. W. Ockwig, H. K. Chae, M. Eddaoudi, J. Kim, Nature, 2003, 423, 705-714.

[20] R. Robson, J. Chem. Soc. Dalton Trans., 2000, 3735-3744.
[21] Y. Sun, H. C. Zhou, Sci. Technol. Adv. Mater., 2015, 16, 054202.

[22] H. Furukawa, K. E. Cordova, M. O'Keeffe, O. M. Yaghi, Science, 2013, $341,1230444$.

[23] N. Stock, S. Biswas, Chem. Rev., 2012, 112, 933-969.

[24] M. Rubio-Martinez, C. Avci-Camur, A. W. Thornton, I. Imaz, D. Maspoch, M. R. Hill, Chem. Soc. Rev., 2017, 46, 3453-3480.

[25] P. Silva, S. M. F. Vilela, J. P. C. Tomé, F. A. Almeida Paz, Chem. Soc. Rev., 2015, 44, 6774-6803.

[26] Y. B. He, B. Li, M. O'Keeffe, B. L. Chen, Chem. Soc. Rev., 2014, 43, 5618-5656.

[27] A. Corma, H. García, F. X. Llabrés i Xamena, Chem. Rev., 2010, 110, 4606-4655.

[28] L. Jiao, Y. Wang, H. L. Jiang, Q. Xu, Adv. Mater., 2017, DOI: 10.1002/adma.201703663.

[29] Y. J. Cui, Y. F. Yu, G. D. Qian, B. L. Chen, Chem. Rev., 2012, 112, 1126-1162.

[30] I. Stassen, N. Burtch, A. Talin, P. Falcaro, M. Allendorf, R. Ameloot, Chem. Soc. Rev., 2017, 46, 3185-3241.

[31] N. Ahmad, H. A. Younus, A. H. Chughtaiabd, F. Verpoort, Chem. Soc. Rev., 2015, 44, 9-25.

[32] S. S. Zheng, X. R. Li, B. Y. Yan, Q. Hu, Y. X. Xu, X. Xiao, H. G. Xue, H. Pang, Adv. Energy Mater., 2017, 7, 1602733.

[33] S. L. Zhao, Y. Wang, J. C. Dong, C. T. He, H. J. Yin, P. F. An, K. Zhao, X. F. Zhang, C. Gao, L. J. Zhang, J. W. Lv, J. X. Wang, J. Q. Zhang, A. M. 
Khattak, N. A. Khan, Z. X. Wei, J. Zhang, S. Q. Liu, H. J. Zhao, Z. Y. Tang, Nat. Energy, 2016, 1, 16184.

[34] E. M. Miner, T. Fukushima, D. Sheberla, L. Sun, Y. Surendranath, M. Dincă, Nat. Commun., 2016, 7, 10942.

[35] L. Wang, Y. Z. Wu, R. Cao, L. T. Ren, M. X. Chen, X. Feng, J. W. Zhou, B. Wang, ACS Appl. Mater. Interfaces, 2016, 8, 16736-16743.

[36] S. Sohrabi, S. Dehghanpour, M. Ghalkhani, ChemCatChem, 2016, 8, 2356-2366.

[37] P. M. Usov, B. Huffman, C. C. Epley, M. C. Kessinger, J. Zhu, W. A. Maza, A. J. Morris, ACS Appl. Mater. Interfaces, 2017, 9, 33539-33543.

[38] H. B. Zhang, J. W. Nai, L. Yu, X. W. Lou, Joule, 2017, 1, 77-107.

[39] S. F. Fu, C. Z. Zhu, J. H. Song, D. Du, Y. H. Lin, Adv. Energy Mater., 2017, 7, 1700363.

[40] K. F. Babu, M. A. Kulandainathan, I. Katsounaros, L. Rassaei, A. D. Burrows, P. R. Raithby, F. Marken, Electrochem. Commun., 2010, 12, 632-635.

[41] C. Wang, Z. G. Xie, K. E. deKraft, W. B. Lin, J. Am. Chem. Soc., 2011, 133, 13445-13454.

[42] J. J. Mao, L. F. Yang, P. Yu, X. W. Wei, L. Q. Mao, Electrochem. Commun., 2012, 19, 29-31.

[43] G. Q. Song, Z. Q. Wang, L. Wang, G. R. Li, M. J. Huang, F. X. Yin, Chin. J. Catal., 2014, 35, 185-195.

[44] H. Wang, F. X. Yin, G. R. Li, B. H. Chen, Z. Q. Wang, Int. J. Hydrogen Energy, 2014, 39, 16179-16186.

[45] G. Férey, C. Mellot-Draznieks, C. Serre, F. Millange, J. Dutour, S. Surblé, I. Margiolaki, Science, 2005, 309, 2040-2042.

[46] B. Nepal, S. Das, Angew. Chem. Int. Ed., 2013, 52, 7224-7227.

[47] F. X. Yin, G. R. Li, H. Wang, Catal. Commun., 2014, 54, 17-21.

[48] X. B. He, F. X. Yin, G. R. Li, Int. J. Hydrogen Energy, 2015, 40, 9713-9722.

[49] H. Wang, F. X. Yin, B. H. Chen, G. R. Li, J. Mater. Chem. A, 2015, 3, 16168-16176.

[50] S. S. Park, E. R. Hontz, L. Sun, C. H. Hendon, A. Walsh, T. V. Voorhis, M. Dincă, J. Am. Chem. Soc., 2015, 137, 1774-1777.

[51] Y. Kobayashi, B. Jacobs, M. D. Allendorf, J. R. Long, Chem. Mater., 2010, 22, 4120-4122.

[52] Z. Yin, Q. X. Wang, M. H. Zeng, J. Am. Chem. Soc., 2012, 134, 4857-4863.

[53] M. Jahan, Q. Bao, K. P. Loh, J. Am. Chem. Soc., 2012, 134, 6707-6713.

[54] M. Jahan, Z. L. Liu, K. P. Loh, Adv. Funct. Mater., 2013, 23, 5363-5372.

[55] H. Wang, F. X. Yin, B. H. Chen, X. B. He, P. L. Lv, C. Y. Ye, D. J. Liu, Appl. Catal. B, 2017, 205, 55-67.

[56] L. Zhao, B. L. Dong, S. Z. Li, L. J. Zhou, L. F. Lai, Z. W. Wang, S. L. Zhao, M. Han, K. Gao, M. Lu, X. J. Xie, B. Chen, Z. P. Liu, X. J. Wang, H. Zhang, H. Li, J. Q. Liu, H. Zhang, X. Huang, W. Huang, ACS Nano, 2017, 11, 5800-5807.

[57] R. Jasinski, Nature, 1964, 201, 1212-1213.

[58] J. Q. Shen, P. Q. Liao, D. D. Zhou, C. T. He, J. X. Wu, W. X. Zhang, J. P. Zhang, X. M. Chen, J. Am. Chem. Soc., 2017, 139, 1778-1781.

[59] Y. V. Kaneti, J. Tang, R. R. Salunkhe, X. C. Jiang, A. B. Yu, K. C. W. Wu, Y. Yamauchi, Adv. Mater., 2017, 29, 1604898.

[60] Y. H. Qian, I. Ali Khan, D. Zhao, Small, 2017, 13, 1701143.

[61] B. Y. Xia, Y. Yan, N. Li, H. B. Wu, X. W. Lou, X. Wang, Nat. Energy, 2016, 1, 15006.

[62] S. H. Liu, Z. Y. Wang, S. Zhou, F. J. Yu, M. Z. Yu, C. Y. Chiang, W. Z. Zhou, J. J. Zhao, J. S. Qiu, Adv. Mater., 2017, 29, 1700874.

[63] Q. X. Lai, J. J. Zhu, Y. X. Zhao, Y. Y. Liang, J. P. He, J. H. Chen, Small, 2017, 13, 1700740 .

[64] W. Xia, J. H. Zhu, W. H. Guo, L. An, D. G. Xia, R. Q. Zou, J. Mater. Chem.
A, 2014, 2, 11606-11613.

[65] L. H. Ai, T. Tian, J. Jiang, ACS Sustainable Chem. Eng., 2017, 5, 4771-4777.

[66] J. Wei, Y. X. Hu, Y. Liang, B. Kong, Z. F. Zheng, J. Zhang, S. P. Jiang, Y. X. Zhao, H. T. Wang, J. Mater. Chem. A, 2017, 5, 10182-10189.

[67] H. Wang, F. X. Yin, P. L. Lv, T. Fan, X. B. He, B. H. Chen, Int. J. Hydrogen Energy, 2017, 42, 2127-2133.

[68] M. Kuang, Q. H. Wang, P. Han, G. F. Zheng, Adv. Energy Mater., 2017, 7, 1700193.

[69] J. K. Nørskov, J. Rossmeisl, A. Logadottir, L. Lindqvist, J. R. Kitchin, T. Bligaard. H. Jónsson, J. Phys. Chem. B, 2004,108, 17886-17892.

[70] T. Y. Ma, S. Dai, M. Jaroniec, S. Z. Qiao, J. Am. Chem. Soc., 2014, 136, 13925-13931.

[71] Xia, R. Q. Zou, L. An, D. G. Xia, S. J. Guo, Energy Environ. Sci., 2015, 8, 568-576.

[72] A. Aijaz, J. Masa, C. Rçsler, W. Xia, P. Weide, A. J. R. Botz, R. A. Fischer, W. Schuhmann, M. Muhler, Angew. Chem. Int. Ed., 2016, 55, 4087-4091.

[73] H. Wang, X. C. Cheng, F. X. Yin, B. H. Chen, T. Y. Fan, X. B. He, Electrochim. Acta, 2017, 232, 114-122.

[74] D. R. Sun, L. Ye, F. X. Sun, H. Garcia, Z. H. Li, Inorg. Chem., 2017, 56, 5203-5209.

[75] J. Deng, D. H. Deng, X. H. Bao, Adv. Mater., 2017, 29, 1606967.

[76] Q. L. Zhu, W. Xia, T. Akita, R. Q. Zou, Q. Xu, Adv. Mater., 2016, 28, 6391-6398.

[77] J. Y. Long, Y. Gong, J. H. Lin, J. Mater. Chem. A, 2017, 5, 10495-10509.

[78] H. Hu, L. Han, M. Z. Yu, Z. Y. Wang, X. W. Lou, Energy Environ. Sci., 2016, 9, 107-111.

[79] T. Meng, J. W. Qin, S. G. Wang, D. Zhao, B. G. Mao, M. H. Cao, J. Mater. Chem. A, 2017, 5, 7001-7014.

[80] P. Li, H. C. Zeng, Chem. Commun., 2017, 53, 6025-6028.

[81] M. M. Wang, M. T. Lin, J. T. Li, L. Huang, Z. C. Zhuang, C. Lin, L. Zhou, L. Q. Mai, Chem. Commun., 2017, 53, 8372-8375.

[82] J. Park, H. Lee, Y. E. Bae, K. C. Park, H. Ji, N. C. Jeong, M. H. Lee, O. J. Kwon, C. Y. Lee, ACS Appl. Mater. Interfaces, 2017, 9, 28758-28765.

[83] J. S. Li, S. L. Li, Y. J. Tang, M. Han, Z. H. Dai, J. C. Bao, Y. Q. Lan, Chem. Commun., 2015, 51, 2710-2713.

[84] S. L. Zhao, H. J. Yin, L. Du, L. C. He, K. Zhao, L. Chang, G. P. Yin, H. J. Zhao, S. Q. Liu, Z. Y. Tang, ACS Nano, 2014, 8, 12660-12668.

[85] B. H. Chen, X. B. He, F. X. Yin, H. Wang, D. J. Liu, R. X. Shi, J. N. Chen, H. W. Yin, Adv. Funct. Mater., 2017, 27, 1700795.

[86] X. B. He, F. X. Yin, J. N. Chen, C. Y. Ye, Inorg. Chem. Front., 2017, 4, 1073-1086.

[87] W. Chaikittisilp, M. Hu, H. J. Wang, H. S. Huang, T. Fujita, K. C. W. Wu, L. C. Chen, Y. Yamauchi, K. Ariga, Chem. Commun., 2012, 48, 7259-7261.

[88] J. Hu, H. L. Wang, Q. M. Gao, H. L. Guo, Carbon, 2010, 48, 3599-3606.

[89] S. J. Yang, T. Kim, J. H. Im, Y. S. Kim, K. Lee, H. Jung, C. R. Park, Chem. Mater., 2012, 24, 464-470.

[90] M. Hu, J. Reboul, S. Furukawa, N. L. Torad, Q. Ji, P. Srinivasu, K. Ariga, S. Kitagawa, Y. Yamauchi, J. Am. Chem. Soc., 2012, 134, 2864-2867.

[91] W. Xia, B. Qiu, D. G. Xia, R. Q. Zou, Sci. Rep., 2013, 3, 1935.

[92] A. Aijaz, N. Fujiwara, Q. Xu, J. Am. Chem. Soc., 2014, 136, 6790-6793.

[93] P. Y. Yin, T. Yao, Y. E. Wu, L. R. Zheng, Y. Lin, W. Liu, H. X. Ju, J. F. Zhu, X. Hong, Z. X. Deng, G. Zhou, S. Q. Wei, Y. D. Li, Angew. Chem. Int. Ed., 2016, 55, 10800-10805.

[94] D. H. Guo, R. Shibuya, C. Akiba, S. Saji, T. Kondo, J. Nakamura, 
Science, 2016, 351, 361-365.

[95] H. B. Yang, J. W. Miao, S. F. Hung, J. Z. Chen, H. B. Tao, X. Z. Wang, L. P. Zhang, R. Chen, J. J. Gao, H. M. Chen, L. M. Dai, B. Liu, Sci. Adv., 2016, 2, e1501122/1-e1501122/11.

[96] X. K. Kong, Q. C. Liu, D. B. Chen, G. L. Chen, ChemCatChem, 2017, 9, 846-852.

[97] Y. Zheng, Y. Jiao, S. Z. Qiao, Adv. Mater., 2015, 27, 5372-5378.

[98] C. Tang, H. F. Wang, X. Chen, B. Q. Li, T. Z. Hou, B. S. Zhang, Q. Zhang, M. M. Titirici, F. Wei, Adv. Mater., 2016, 28, 6845-6851.

[99] P. Zhang, F. Sun, Z. H. Xiang, Z. G. Shen, J. Yun, D. P. Cao, Energy Environ. Sci., 2014, 7, 442-450.

[100] Y. H. Qian, Z. G. Hu, X. M. Ge, S. L. Yang, Y. W. Peng, Z. X. Kang, Z. L. Liu, J. Y. Lee, D. Zhao, Carbon, 2017, 111, 641-650.

[101] J. S. Li, Y. Y. Chen, Y. J. Tang, S. L. Li, H. Q. Dong, K. Li, M. Han, Y. Q. Lan, J. C. Bao, Z. H. Dai, J. Mater. Chem. A, 2014, 2, 6316-6319.

[102] J. S. Li, S. L. Li, Y. J. Tang, K. Li, L. Zhou, N. Kong, Y. Q. Lan, J. C. Bao, Z. H. Dai, Sci. Rep., 2014, 4, 5130.

[103] L. J. Zhang, Z. X. Su, F. L. Jiang, L. L. Yang, J. J. Qian, Y. F. Zhou, W. M. Li, M. C. Hong, Nanoscale, 2014, 6, 6590-6602.

[104] A. D. Tan, Y. F. Wang, Z. Y. Fu, P. Tsiakaras, Z. X. Liang, Appl. Catal. $B, \mathbf{2 0 1 7}, 218,260-266$.

[105] Q. X. Lai, Y. X. Zhao, Y. Y. Liang, J. P. He, J. H. Chen, Adv. Funct. Mater., 2016, 26, 8334-8344.

[106] L. Ye, G. L. Chai, Z. H. Wen, Adv. Funct. Mater., 2017, 27, 1606190.

[107] L. J. Li, P. C. Dai, X. Gu, Y. Wang, L. T. Yan, X. B. Zhao, J. Mater. Chem. A, 2017, 5, 789-795.

[108] W. Zhang, Z. Y. Wu, H. L. Jiang, S. H. Yu, J. Am. Chem. Soc., 2014, $136,14385-14388$.

[109] Z. X. Song, W. W. Liu, N. C. Cheng, M. Norouzi. Banis, X. Li, Q. Sun, B. W. Xiao, Y. L. Liu, A. Lushington, R. Y. Li, L. M. Liu, X. L. Sun, Mater. Horiz., 2017, 4, 900-907.

[110] P. M. Huang, H. D. Li, X. Y. Huang, D. Y. Chen, ACS Appl. Mater. Interfaces, 2017, 9, 21083-21088.

[111] J. Liang, Y. Jiao, M.Jaroniec, S. Z. Qiao, Angew. Chem. Int. Ed., 2012, 51, 11496-11500.

[112] K. G. Qu, Y. Zheng, S. Dai, S. Z. Qiao, Nano Energy, 2016, 19, 373-381.

[113] L. Han, X. Y. Yu, X. W. Lou, Adv. Mater., 2016, 28, 4601-4605.

[114] C. Guan, X. M. Liu, W. N. Ren, X. Li, C. W. Cheng, J. Wang, Adv. Energy Mater., 2017, 7, 1602391.

[115] M. Abirami, S. M. Hwang, J. Yang, S. T. Senthilkumar, J. Kim, W. S. Go, B. Senthilkumar, H. K. Song, Y. Kim, ACS Appl. Mater. Interfaces, 2016, 8, 32778-32787.

[116] Y. N. Guo, J. Tang, H. Y. Qian, Z. L. Wang, Y. Yamauchi, Chem. Mater., 2017, 29, 5566-5573.
[117] X. B. Liu, Y. C. Liu, L. Z. Fan, J. Mater. Chem. A, 2017, 5, 15310-15314.

[118] J. W. Nai, Y. Lu, L. Yu, X. Wang, X. W. Lou, Adv. Mater., 2017, 29, 1703870.

[119] M. J. Liu, J. H. Li, ACS Appl. Mater. Interfaces, 2016, 8, 2158-2165.

[120] J. Zhou, Y. B. Dou, A. Zhou, R. M. Guo, M. J. Zhao, J. R. Li, Adv. Energy Mater., 2017, 7, 1602643.

[121] J. Masa, P. Weide, D. Peeters, I. Sinev, W. Xia, Z. Sun, C. Somsen, M. Muhler, W. Schuhmann, Adv. Energy Mater., 2016, 6, 1502313.

[122] J. Yu, Q. Q. Li, Y. Li, C. Y. Xu, L. Zhen, V. P. Dravid, J. S. Wu, Adv. Funct. Mater., 2016, 26, 7644-7651.

[123] A. Ambrosi, M. Pumera, Adv. Funct. Mater., 2017, DOI: 10.1002/adfm.201700655.

[124] W. B. Lu, T. T. Liu, L. Xie, C. Tang, D. N. Liu, S. Hao, F. L. Qu, G. Du, Y. J. Ma, A. M. Asiri, X. P. Sun, Small, 2017, 13, 1700805.

[125] C. Z. Zhu, S. F. Fu, Q. R. Shi, D. Du, Y. H. Lin, Angew. Chem. Int. Ed., 2017, 56, 13944-13960.

[126] H. B. Zhang, G. G. Liu, L. Shi, J. H. Ye, Adv. Energy Mater., 2018, 8, 1701343.

[127] Y. J. Chen, S. F. Ji, Y. G. Wang, J. C. Dong, W. X. Chen, Z. Li, R. A. Shen, L. R. Zheng, Z. B. Zhuang, D. S. Wang, Y. D. Li, Angew. Chem. Int. Ed., 2017, 56, 6937-6941.

[128] H. G. Zhang, S. Hwang, M. Y. Wang, Z. X. Feng, S. Karakalos, L. L. Luo, Z. Qiao, X. H. Xie, C. M. Wang, D. Su, Y. Y. Shao, G. Wu, J. Am. Chem. Soc., 2017, 139, 14143-14149.

[129] S. Dou, C. L. Dong, Z. Hu, Y. C. Huang, J. I. Chen, L. Tao, D. F. Yan, D. W. Chen, S. H. Shen, S. L. Chou, S. Y. Wang, Adv. Funct. Mater., 2017, 27, 1702546 .

[130] D. W. Feng, Z. Y. Gu, J. R. Li, H. L. Jiang, Z. W. Wei, H. C. Zhou, Angew. Chem. Int. Ed., 2012, 51, 10307-10310.

[131] H. L. Jiang, D. W. Feng, K. C. Wang, Z. Y. Gu, Z. W. Wei, Y. P. Chen, H. C. Zhou, J. Am. Chen. Soc., 2013, 135, 13934-13938.

[132] H. X. Deng, S. Grunder, K. E. Cordova, C. Valente, H. Furukawa, M. Hmadeh, F. Gándara, A. C. Whalley, Z. Liu, S. Asahina, H. Kazumori, M. O’Keeffe, O. Terasaki, J. F. Stoddart, O. M. Yaghi, Science, 2012, 336, 1018-1023.

[133] L. F. Song, J. Zhang, L. X. Sun, F. Xu, F. Li, H. Z. Zhang, X. L. Si, C. L. Jiao, Z. B. Li, S. Liu, Y. L. Liu, H. Y. Zhou, D. L. Sun, Y. Du, Z. Cao, Z. Gabelica, Energy Environ. Sci., 2012, 5, 7508-7520.

[134] D. Bradshaw, S. El-Hankari, L. Lupica-Spagnolo, Chem. Soc. Rev., 2014, 43, 5431-5443.

[135] D. F. Yan, Y. X. Li, J. Huo, R. Chen, L. M. Dai, S. Y. Wang, Adv. Mater, 2017, 29, 1606459.

[136] C. M. Yu, P. P. Zhang, J. M. Wang, L. Jiang, Adv. Mater., 2017, 29, 1703053.

\section{高效氧催化反应中的金属有机骨架材料}

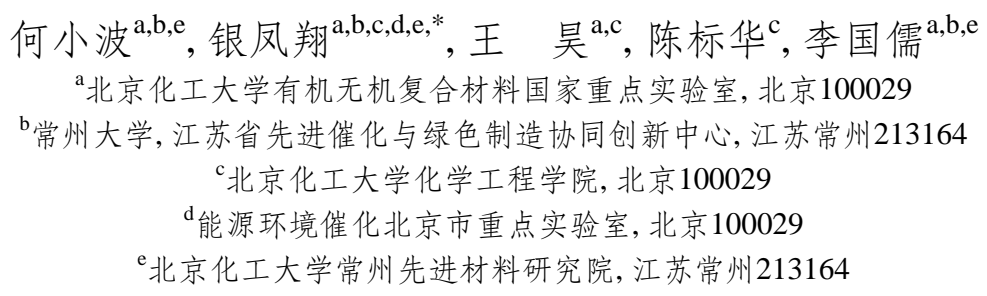

摘要: 氧电催化反应包括氧气还原反应(ORR)和氧气析出反应(OER). 作为核心电极反应, 这两个反应对诸多能源存储与 转换技术(比如燃料电池、金属空气电池以及全水分解制氢等)的能量效率起决定性作用. 然而, ORR和OER涉及多个反应 步骤、多个电子转移过程以及多相界面传质过程. 这些复杂的过程较大程度上限制了 ORR和OER的反应速率. 从理论和实 践两个方面来看, ORR和OER都需要高效电催化剂的参与来促进其反应速率, 从而能够最终提高上述能源存储与转换技术 
的能量转换或利用效率.

目前, 以 Pt, Pd, Ir, Ru为代表的贵金属基电催化剂具有十分突出的电催化性能. 但是, 过高的成本和过低的储量始终制 约着贵金属基电催化剂在催化ORR和OER反应方面, 乃至在能源存储与转换技术领域的规模化应用. 因而, 开发高效非贵 金属基氧电催化剂成为近年来能源存储与转换领域的研究重点之一. 在众多已经报道的非贵金属基氧电催化剂中, 金属 有机骨架材料(MOFs)备受瞩目. MOFs是一类由有机配体和金属节点通过配位键自组装而成的晶态多孔材料. 它们具备 超高比表面积、超高孔隙率以及规则性纳米孔道. 相比较其他传统的多孔材料(比如活性炭、分子䇻、介孔炭、介孔氧化 硅等), MOFs最主要的优势在于它们的结构和功能可以依据需求通过选择合适的有机配体和金属节点进行便利地设计, 或 通过后处理进行必要的改性和调节. 基于独特的多孔特性以及结构与功能的可设计、可调节性, MOFs在气体分离与存储、 异相催化、化学传感、药物输送、环境保护以及能源存储与转化等领域都具有潜在的应用价值. 因而, 近年来, MOFs备受 基础研究领域和工业界的青睐. 针对MOFs开展的基础研究和应用开发逐渐成为诸多领域的研究焦点. 也正由于MOFs具 有的上述优异特性, 尤其是结构与功能的可设计、可调节性, 使得设计制备基于单纯MOFs以及MOFs衍生材料成为开发高 效非贵金属基氧电催化剂的新途径.

本综述首先论述了基于单纯MOFs的氧电催化剂(包括纯MOFs、活性物种修饰的MOFs以及与导电材料构成的复合 MOFs)的合成以及它们在ORR或OER催化反应中应用的研究进展. 在第二部分论述中, 本综述主要针对MOFs衍生的各类 氧电催化剂(包括无机微米-纳米结构/多孔碳复合材料、纯多孔碳材料、纯无机微米-纳米结构材料以及单原子型电催化材 料)的研究进展进行了简要介绍和讨论. 最后, 本综述对MOFs基氧电催化剂目前存在的挑战进行了简要分析; 同时, 也对 这类氧电催化剂的通用设计准则以及未来发展方向进行了展望. 尽管存在诸多挑战, MOFs始终被认为是极好的“平台”材 料. 充分利用它们将有利于开发高效且实用的非贵金属基氧电催化剂.

关键词: 金属有机骨架材料; 多孔材料; 电催化; 氧气还原反应; 氧气析出反应; 能源存储与转换

收稿日期: 2017-10-30. 接受日期: 2017-12-26. 出版日期: 2018-02-05.

*通讯联系人. 电话: (010)64412054; 传真: (010) 64419619; 电子信箱: yinfx@mail.buct.edu.cn

基金来源：国家自然科学基金(21706010); 江苏省基础研究计划(自然科学基金)(BK20161200); 中央高校基本科研业务费项目 (buctrc201526, PYCC1706); 常州市科技项目(CJ20160007); 常州大学江苏省先进催化与绿色制造协同创新中心创新型人才支持 项目(ACGM2016-06-02, ACGM2016-06-03).

本文的电子版全文由Elsevier出版社在ScienceDirect上出版(http://www.sciencedirect.com/science/journal/18722067). 